\title{
Growth theory under heterogeneous heuristic behavior
}

\section{Orlando Gomes ${ }^{1,2}$}

Published online: 02 June 2020

(c) Springer-Verlag GmbH Germany, part of Springer Nature 2020

\begin{abstract}
Over the last decades, conceptual frameworks formulated to address the dynamics of economic growth have hypothesized, discussed and tested a large number of different assumptions concerning the role of capital accumulation, labor productivity, learning-by-doing, formal education, innovation, and diffusion of ideas. Underlying all these theoretical contributions is, on the demand side, a pervasive and apparently unshakable structure of analysis: economic agents invariably set an optimal intertemporal consumption plan which allows then to maximize utility over an infinite horizon. Such behavior, however, suggests a planning ability that agents often lack. In fact, household decisions are frequently designed on the basis of heuristics or rules-of-thumb that, although not optimal, are reachable under the cognitive constraints typically faced by human beings. This paper revisits some of the most prominent models of the mainstream growth theory, taking a specific heuristic to account for consumption-savings decisions. The heuristic, which allows for the consideration of distinct profiles of saving behavior across individual agents, is a static rule, which might suggest a return to a Solow-like growth analysis. Notwithstanding, the adopted rule-of-thumb encloses a series of novel and relevant implications for growth theory. Such implications are duly highlighted and discussed in this study.
\end{abstract}

Keywords Growth theory · Consumption-savings heuristic · Non-optimal growth · Intertemporal choice $\cdot$ Neoclassical growth $\cdot$ Endogenous growth

JEL Classification O41 - E21

Orlando Gomes

omgomes@iscal.ipl.pt

1 Lisbon Accounting and Business School (ISCAL/IPL), Lisbon, Portugal

2 CEFAGE - ISCAL/IPL research center, Évora, Portugal 


\section{Introduction}

In a short survey on the history of contemporaneous economic growth theory, (Akcigit 2017), p. 1736 emphasizes that

Economies are complex systems resulting from the actions of many actors. This complexity makes it challenging, but also infinitely interesting, to understand the determinants of economic growth. What are the roles of human capital, fertility, ideas, basic science, and public policy for growth?

This sentence highlights two important points: first, understanding patterns of economic growth and their underlying determinants is not a trivial task because economies are evolving complex entities, ${ }^{1}$ second, drivers of long-term growth are essentially supply-side variables subject to specific processes of accumulation and renewal, such as human capital or scientific knowledge. Agreeing with the first claim raises the question of whether the second one could somehow be perceived as restrictive, in the sense that fully understanding growth might require, as well, taking a careful look at the demand side and at the behavior of consumers and the cognitive challenges they face.

Following the pioneer contributions of Solow (1956) and Swan (1956), who approached growth dynamics under the simplifying assumption of a constant savings rate, practically all the subsequent research has been built upon a utility maximization framework, where consumption-savings choices are endogenously determined. This framework allows agents (often a representative agent) to compute and follow optimal intertemporal consumption trajectories. Growth models designed under this perspective are optimal growth models, meaning that the underlying growth rates emerge from the optimal decisions of rational agents with unlimited planning capabilities.

The presence of the utility maximization setup in growth analyses is ubiquitous, from neoclassical growth (Cass 1965; Koopmans 1965), to the various classes of endogenous growth models (Romer 1987; 1990; Lucas 1988; Grossman and Helpman 1991; Rebelo 1991; Aghion and Howitt 1992; Jones 1995), and to the most recent wave of growth theory that explores the implications and consequences of agent heterogeneity concerning skills, productivity and innovative capabilities (Kim and Song 2014; Zeira and Zoabi 2015; Jaimovich and Rebelo 2017; Acemoglu et al. 2018; Akcigit and Kerr 2018; Grossman and Helpman 2018).

Such a constancy in the demand structure has been helpful in allowing growth theorists to concentrate attention in relevant aspects of the growth process and of the forces driving long-term growth. State-of-the-art economic growth research includes the work of Lucas (2009, 2015), Lucas and Moll (2014), and Buera and Lucas (2018), on the dissemination of ideas and learning through decentralized interaction; the con-

\footnotetext{
${ }^{1}$ See Sequeira et al. (2018) for an effort to integrate and explore the role of complexity in standard dynamic growth analysis, namely, in the context of an endogenous growth model. Studies on agent-based evolutionary growth e.g., Dosi et al. (2010, 2013), Guerini et al. (2018), to which we will come back later, also interpret the economy as a complex evolving system.
} 
tributions of Acemoglu and Cao (2015), Aghion et al. (2015), and Akcigit et al. (2016), on the organization of industries and endogenous technological change; and, among others, the studies and reflections of Aghion and Roulet (2014), Benhabib et al. (2014), Grossman and Helpman (2015), and Stokey (2015), on the issue of international income convergence and divergence, and on how these processes are driven by innovation and imitation.

The above mentioned references constitute inescapable contributions for the advancement of growth theory. However, they invariably lack a careful look into the consumption-savings choices of households and how these can impact long-term growth paths. This paper offers a contribution in the mentioned direction, by abandoning the typical optimization setup and considering, instead, a static consumption heuristic that allows for behavioral heterogeneity. Households hold different psychological profiles and, consequently, their behavior concerning consumption-savings choices is also distinct from one another. ${ }^{2}$ The thesis to explore is grounded on the premise that economic agents are not ruthless optimizers and that they tend to adopt simple idiosyncratic choice rules. The corollary of this premise is that behavior matters to growth and helps shape transitional dynamics and long-term equilibrium outcomes.

One might jump to the conclusion that analyzing growth through the lens of a static consumption rule is nothing more than a return to a Solow-like exogenous savings rate setting; however, as will be revealed, the interesting point is that there is more than meets the eye in adopting such an approach for the analysis of economic growth. By taking a tour through a sequence of typical growth models (one-sector neoclassical growth model, $A K$ endogenous growth model, two-sector human capital endogenous growth model, and a growth model with labor-replacing capital), and modifying them in order to contemplate the consumption heuristic, we identify relevant implications concerning intertemporal preferences, transitional dynamics, steady-state growth, and heterogeneity of outcomes.

Placing the focus on decision-making and assuming the type of rule that is explored, it becomes possible to investigate how psychological profiles in a population might determine long-term growth. Agents are endowed with a sentiment level that translates the extent in which they value future consumption against current consumption. While some appreciate saving and opt to differ consumption in time, others are impatient and prefer to concentrate consumption the closest as possible to the current time period. The economy is populated by the two types of households and it is this diversity that allows to add relevant insights to growth analysis. Sentiment heterogeneity and changes in sentiments are certainly a relevant determinant of the decisions of agents and, thus, also of the aggregate outcomes in the economy, whether these sentiments are associated with consumption-savings decisions, as is

\footnotetext{
${ }^{2}$ See Gerhard et al. (2018) for an empirical characterization of the psychological drivers of savings. In particular, these authors identify the following relevant psychological characteristics as determinants of savings behavior: personality traits (agreableness, conscientiousness, extraversion, neuroticism, openess to experience), self-control, optimism, attitude towards savings, and regulatory focus. These features vary across individual agents (for genetic reasons and due to socialization), thus generating distinct savings profiles.
} 
the case, or with investment choices as explored in some growth-related literature, most prominently in (Martin and Ventura 2012).

The inspiration underlying the research in this paper can be found in the confluence of two strands of literature, which are briefly reviewed in Section 2. The first strand, the permanent income / life-cycle theory and the debate around its adequacy to interpret and explain consumption-savings choices of actual households, serves as the main support to dismiss optimal planning in favor of a simple choice rule. In fact, the heuristic to adopt is inspired by (Deaton 1992) suggestion that people save a share of their income if, and only if, income is higher than expected. As will be revealed, the proposed heuristic differs from Deaton's rule in a series of respects (it is a deterministic rule; the element driving choices is a desired consumption threshold that varies across households and not a rational expectation on future income). However, it emanates from a same principle that agents save a share of their excess income (in this case, relatively to a psychological threshold) and, otherwise, if income is below the threshold, do not save at all.

The second strand of literature that is relevant in the present context is the agentbased evolutionary growth theory initiated by the work by Dosi et al. (2010). This theory merges demand-driven features of a Keynesian inspiration with the Schumpeterian notions of innovation, entrepreneurship, and creative destruction. This theory matters for the current analysis because it involves behavior heterogeneity across individual agents and the use of simple rules of behavior that replace optimal planning. Heterogeneity and simple decision rules are indelible characteristics of the agent-based (bottom-up) approach pursued in the evolutionary growth tradition.

The remainder of the paper is organized as follows. Section 2 addresses the relevance of adopting consumption heuristics to explain decision-making processes. Section 3 discusses the rationale underlying the assumption of heterogeneity at the psychological level. Sections 4 to 7 explore growth dynamics under the suggested heuristic, assuming, consecutively, a neoclassical growth model, the AK endogenous growth model, a two-sector endogenous growth model of the Uzawa (1965) - Lucas (1988) type, and a two-sector model with robotic capital. Section 8 concludes.

\section{There is nothing optimal about them: rule-based consumption-savings decisions}

Whether economic agents are rational optimizers or, instead, cognitively constrained decision-makers who base their decisions in simple heuristics is a long-lasting scientific debate. Although the benchmark paradigm in economic analysis is one in which the maximization of a pre-specified objective function occupies center stage, empirical observation often contradicts the idea that optimal behavior is, in fact, a reasonable research assumption. Consequently, economic thinking has evolved: standard dynamic programming settings have been, and continue to be, progressively complemented or replaced by behavioral contexts in which agents act and react in ways that are consistent with observable, real life, decision-making processes.

Conceptual and practical discussions on the merits of rules-of-thumb versus intertemporal optimization as a pathway to characterize judgements, decisions and 
actions of agents and their respective consequences abound in the literature. They go back to Simon (1955), Tversky and Kahneman (1974), Ellison and Fudenberg (1993), Krusell and Smith (1996), and Lettau and Uhlig (1999), just to cite some of the most prominent studies published on this matter along the second half of the twentieth century. Currently, the optimization / heuristics controversy continues to be fueled by meaningful contributions e.g., De Grauwe (2011), Gabaix (2014). These contributions have in common the perception that economic agents, even those well equipped to collect and process information (e.g., large firms or government institutions), are unable to cope with a world that is too vast and too complex to be fully understandable and manageable by anyone. In this scenario, the use of heuristics or rules-of-thumb is not a symptom of irrationality; it is rather a rational response of agents who are aware of their limited capacity to understand the world. (De Grauwe, 2011, p. 425).

Heuristics are fast and frugal rules to which decision-makers resort, given the information, knowledge, and time constraints they invariably face. In many circumstances, deep, careful, and lengthy deliberation are luxuries decision-makers cannot afford and, thus, it pays off to trade accuracy for less effort (Gigerenzer and Todd 1999; Gigerenzer and Selten 2002). A surprising discovery in this context is the lessis-more principle (Gigerenzer 2008; Gigerenzer and Brighton 2009; Gigerenzer and Gaissmaier 2011), according to which, in many scenarios, less processing might lead to better inferences. If less time, information, and computation can improve accuracy, this means that heuristics are not necessarily second-best approximations to optimal planning. Therefore, there is no reason to consider them as an element of irrationality that should be avoided in economic analysis. On the contrary, they constitute a potentially precise and robust tool for inference and decision that often outperform sophisticated forecasting mechanisms based in strict notions of rationality. The influence of the less-is-more principle led economists to change their perspective over many economic issues; e.g., Dosi et al. (2017) study the macroeconomic impact of forming expectations and taking decisions under the use of simple rules-of-thumb.

Despite the consensus that pure optimization is not truly reflexive of how agents are capable of behaving when faced with complex and multidimensional choices, the truth is that mainstream economic growth theory has never abandoned its prototypical framework, which basically consists in an optimal control problem where a representative agent, or a pre-specified array of heterogeneous agents, establishes a plan to maximize consumption utility from the current period all the way over some future date (possibly an infinite horizon). What distinguishes different growth models is, in this perspective, essentially the set of constraints to which the maximization of the objective function is subject. Putting into question the object of optimization (consumption utility) or the fact that optimization itself is feasible, is much rarer in growth analysis.

The inspiration for the current study comes from two distinct lines of research. The first is associated with the often highlighted paradox emerging in permanent income / life-cycle models of consumption and savings, concerning the feasibility of the standard intertemporal optimization problem. Winter et al. (2012, p. 479) provide a synthesis of the issue at hand, 
the solution of the underlying intertemporal optimization problem is rather complicated. It requires backwards induction, and no closed-form solution for current consumption as a function of the relevant state variables exists. Many authors argue that individuals are unable to perform the calculations which are required to solve the underlying intertemporal optimization problem by backwards induction

Computational obstacles associated with the search for the optimal solution have directed researchers in the permanent income / life-cycle tradition to wonder whether flesh-and-bone agents use simple rules-of-thumb, instead of sophisticated intertemporal optimization procedures, to decide how much to consume in each time period. Empirical evidence is mixed: the seminal work by Campbell and Mankiw (1990) suggests that households indeed follow simple rules when deciding how much to consume and save. However, contributions discussing this result are not unanimous, with, e.g., Weber (2000) and Weber (2002) claiming that the use of rules-of-thumb in consumption, at least the type of rules implying a large percentage of individuals simply consuming their current income, does not encounter support in the data.

In the context of the life-cycle theory, Deaton (1992) suggests an intuitive consumption rule, involving low computational costs and capable of performing nearly as well as the solution for the optimal problem. In the choice of his consumption rule, Deaton (1992, p. 257) elucidates that

My choice of rule of thumb is not arbitrary, but was guided to some extent by knowledge of the optimal function. (...) My concern is more that the rule should be simple, simple enough to have plausibly evolved from trial and error.

Following the notation in Winter et al. (2012), Deaton's heuristic assumes the form

$$
C(t)=\left\{\begin{array}{l}
X(t) \text { if } Y(t) \leq E[Y(t)] \text { and } X(t) \leq E[Y(t)] \\
E[Y(t)] \text { if } Y(t) \leq E[Y(t)] \text { and } X(t)>E[Y(t)] \\
E[Y(t)]+\zeta\{Y(t)-E[Y(t)]\} \text { if } Y(t)>E[Y(t)]
\end{array}\right.
$$

In equation (1), $C(t)$ stands for consumption, and variable $X(t)$ represents cash-onhand, i.e., the sum of income, $Y(t)$, with the assets held by the agent(s), which, in a general equilibrium growth perspective have correspondence to the value of the available amount of productive capital, $K(t)$. Consumption rule (1) states that agents only save whenever the expected income, $E[Y(t)]$, exceeds effective income, and they save a fraction $1-\zeta \in(0,1)$ of the excess income. Otherwise, agents will consume an amount that is identical to the expected level of income or to cash-onhand, depending on the values of each of these two variables.

Deaton's consumption rule is a simple straightforward rule; it is not forwardlooking, it overlooks intertemporal preferences, and it appears to be formulated in an ad-hoc way. Nevertheless, when attributing a value to parameter $\zeta$ near $30 \%$, the rule allows, as highlighted by its creator, for a good replication of observed patterns of households' consumption and savings. It is this rule that will serve as benchmark for the formulation of a consumption heuristic in the next section, which will be a fundamental piece for the growth analysis that will then follow. Substantial adaptations will be made to the meaning of (1), although the structure of the rule will be similar. 
A second strand of literature on which the analysis in this paper relies is the agent-based evolutionary growth class of models, developed by, among others, Dosi et al. (2010, 2013, 2015, 2019), Dawid et al. (2014), Dawid et al. (2018), Ciarli et al. (2019), and Lamperti et al. (2018). This class of growth models combines demand-side Keynesian features with endogenous technological change of a creativedestruction (Schumpeterian) nature. This approach to growth dynamics requires taking a bottom-up methodological perspective, i.e., an agent-based setup in which heterogeneous agents adopt simple behavioral rules and interact in a complex world. In the words of Dosi et al. (2013, p. 1599),

Our approach considers the economy as a complex evolving system, i.e. as an ecology of heterogenous agents whose far from-equilibrium interactions continuously change the structure of the system itself (...). In this framework, the statistical relationships exhibited by macroeconomic variables should be considered as emergent properties stemming from microeconomic disequilibrium interactions.

A fundamental feature of the agent-based approach to growth is the relevance attributed to the use of simple heuristics. In Dawid et al. (2019) and Dosi and Roventini (2019), cognitive constraints of economic agents are highlighted: households, firms and institutions behave according to heuristics that are formulated taking into account the limited knowledge they have about the surrounding environment and about their own history. Agent-based approaches to macroeconomics and growth attribute particular attention to consumption heuristics, as we do in the current analysis. Although we will focus on a modified version of the Deaton's rule as discussed above, there is a large variety of different rules that may apply more or less effectively to distinct scenarios. Table 2 in Haldane and Turrell (2019) presents a thorough list of heuristics proposed in the literature to characterize consumption-savings choices.

\section{Are we all alike? A world of ants and grasshoppers}

In typical growth analyses, economies are populated by identical agents or, what is the same, by a representative agent. This is a straightforward corollary of the assumption of strict rationality and optimal behavior. Allowing for the use of decision heuristics opens the door for heterogeneity: while there is only one possible way of acting optimally, there is a multiplicity of ways in which a rule-of-thumb might be specified and implemented. We concur with Winter et al. (2012, p. 498) when stating that

Any empirical analysis of rule-of-thumb saving behaviour would have to account for the possibility that individuals are heterogeneous with respect to the decision rules they use. Once we give up the fiction of optimal behaviour based on the solution to a (unique) underlying optimisation problem, the result that all individuals follow the same decision rule does not need to hold any more.

To assemble a consistent and useful consumption-savings heuristic mixed with behavioral agent heterogeneity, we begin by assuming that each agent is endowed 
with a unique life philosophy or conception of the world (as a result of their upbringing, education, life experiences and even genetics). The worldview of the individual agent or his life-style choice will then determine the respective intertemporal pattern of consumption and savings. Specifically, we consider that people can be, as in Aesop's fable, grasshoppers, who live for the short-run and do not plan for the future, or, alternatively, ants, who store part of their income under the form of savings that allow them to sustain higher future consumption levels. Those who act as grasshoppers do not care especially about what the future might bring, while ants are the allegorical figures that represent those who believe saving is the proper path to guarantee the perpetuation of consumption in future dates.

Evidently, households might be grasshoppers or ants in different degrees (closer to a neutrality state or taking a relatively extreme position in any of the two directions). Moreover, they do not necessarily remain forever in the same state; they might evolve, e.g. as the result of social contagion or of the self-assessment of the consequences of their actions under the state into which they find themselves. ${ }^{3}$

Formally, let $x \in \mathbb{R}$ be a psychological profile index, such that $x=0$ represents a state of neutrality, $x>0$ defines a grasshopper, and $x<0$ defines an ant, following the notions presented above. The larger $x$ is, in absolute value, the more extreme the sentiment or worldview will be. This interpretation allows us to adapt rule (1), presented in the previous section, to the growth environment one intends to construe. The rule is modified through the replacement of the expectation on the value of income by a desired consumption threshold level, $C(t, d)$, which is defined as

$$
C(t, d) \equiv Y(t) e^{x}
$$

Equation (2) is interpretable as follows: for $x=0$, the household desires a consumption level that equals his income; this state is designated as state of neutrality. Whenever $x>0$, the desired consumption level is higher than the effective current income (this is the actual definition of a grasshopper); in the opposite case, $x<0$, the consumption threshold is lower than current income, which characterizes the lifestyle choice of ants, who will save a share of the income earned. Replacing $C(t, d)$ into equation (1), the consumption heuristic for the growth analysis that follows is obtained,

$$
C(t)=\left\{\begin{array}{l}
K(t)+Y(t) \text { if } x \geq \ln \left[1+\frac{K(t)}{Y(t)}\right] \\
e^{x} Y(t) \text { if } 0 \leq x<\ln \left[1+\frac{K(t)}{Y(t)}\right] \\
{\left[e^{x}+\zeta\left(1-e^{x}\right)\right] Y(t) \text { if } x<0}
\end{array}\right.
$$

Equation (3) indicates that ants save a share $1-\zeta$ of the difference between income and the consumption threshold, i.e., they save a percentage $(1-\zeta)\left(1-e^{x}\right)$ of income. This share is higher the higher the value of $x$ in absolute value; extreme

\footnotetext{
${ }^{3}$ The dynamics of the distribution of the worldviews might be interpreted as an evolutionary process that can be modeled, e.g., under a discrete choice switching mechanism as the one proposed by Brock and Hommes (1997). The growth models to explore in the following sections focus on the impact of heterogeneous savings behavior over growth dynamics, but they overlook the analysis of the dynamics of the distribution of worldviews. Although this is a relevant topic of research, it is left for future work.
} 
ants will save more than moderate ants. Grasshoppers spend more than the income they receive; extreme grasshoppers, for whom $x \geq \ln \left[1+\frac{K(t)}{Y(t)}\right]$, will consume all their cash-on-hand at period $t$.

\section{Neoclassical growth: a modified Solow-Swan setting}

Assume a decentralized economy in which time flows continuously. This economy is populated by an unspecified large number of infinitely-lived households, indexed in the interval $[0, L]$; for convenience, $L$ is assumed constant. Following the discussion in the previous section, the only eventual distinguishing feature among households is their sentiment level / worldview index. The amount of households experiencing sentiment $x$ will be represented by $L(x) \leq L$. On the supply-side, in turn, we take the simplifying assumption that all output is generated by a single representative firm. This firm produces a homogeneous good that can be either consumed or invested to generate additional physical capital.

Households inelastically supply labor and rent the capital they own to the representative firm. Both the labor market and the rental market are competitive, with $w(t)$ and $r(t)$ representing the competitive wage rate and the competitive gross rental rate. Labor endowments, with respect to each sentiment class, are assumed constant over time, while capital endowments evolve under rule

$$
\dot{K}(t, x)=I(t, x)-\delta K(t, x), \quad K(0, x)=K_{0}(x) \text { given }
$$

In equation (4), $K(t, x)$ and $I(t, x)$ stand for the capital stock held by the group of agents in class $x$ and for the respective flow of investment; $\delta \in[0,1]$ stands for the capital depreciation rate. In a closed economy with no government, investment fully originates in the household's savings, i.e. $I(t, x)=Y(t, x)-C(t, x)$, with $Y(t, x)$ and $C(t, x)$ defining the income and consumption levels of the set of households in class $x$. Income has two components, labor returns and capital returns; therefore,

$$
Y(t, x)=w(t) L(x)+r(t) K(t, x)
$$

If agents are homogeneous with respect to their labor productivity and if no frictions exist in capital markets, the wage rate and the rental rate introduced in equation (5) are identical across households, regardless of the sentiment class to which they belong.

In this economy, the representative firm rents capital and recruits labor in competitive capital and labor markets, with the goal of producing a competitive homogeneous good that it sells to households. The firm's production function is a continuous and twice differentiable function $F: \mathbb{R}_{+}^{2} \rightarrow \mathbb{R}_{+}$with capital and labor as inputs,

$$
Y(t)=F[K(t), L]
$$


In equation (6), $K(t)$ and $Y(t)$ represent, respectively, the economy's capital stock and the economy's output, which, under market clearing, are identical to the sum of the households' capital stocks and income levels, i.e.,

$$
\begin{aligned}
& K(t)=\int_{x \in \mathbb{R}} K(t, x) d x \\
& Y(t)=\int_{x \in \mathbb{R}} Y(t, x) d x
\end{aligned}
$$

The firm solves a straightforward static optimization problem; at each date it maximizes profits, expressed as:

$$
\Pi(t)=F[K(t), L]-w(t) L-r(t) K(t)
$$

The computation of optimality conditions for the maximization of (9) uncovers the competitive levels of the wage and of the rental rate, which are, simply, $w(t)=F_{L}$; $r(t)=F_{K}$.

The information collected so far is systematized in the following definition.

Definition 1 The collection of trajectories $\left\{[K(t, x), I(t, x), C(t, x), Y(t, x)]_{x \in \mathbb{R}}\right\}_{t=0}^{\infty}$, and the trajectories of the respective aggregate levels, define the equilibrium of the economy, which originates in: (i) consumption-savings choices of households within sentiment class $x, \forall x \in \mathbb{R}$; (ii) representative firm profit maximization; and (iii) market clearing in both capital and labor markets.

On the aggregate, the equilibrium translates into a typical physical capital accumulation dynamic constraint,

$$
\dot{K}(t)=Y(t)-C(t)-\delta K(t), \quad K(0)=K_{0} \text { given }
$$

with

$$
C(t)=\int_{x \in \mathbb{R}} C(t, x) d x
$$

The pattern of growth in the characterized economy is contingent on: (i) the production technology, i.e., the shape of the production function; and (ii) the behavior of households, concerning consumption-savings choices. Relative to this second item, we adopt the consumption heuristic formally presented in Section 3. In what respects the production function, we will, for now, evaluate the growth problem under a neoclassical production function. The following definition applies.

Definition 2 Neoclassical growth under heterogeneous heuristic behavior materializes into the dynamics underlying equation (10), subject to consumption rule (3) and to output being generated through production function (6), with $F[\epsilon K(t), \epsilon L]=$ $\epsilon F[K(t), L], \forall \epsilon>0 ; F_{K}>0, F_{L}>0, F_{K K}<0, F_{L L}<0 ; \lim _{K \rightarrow 0}\left(F_{K}\right)=$ $\lim _{L \rightarrow 0}\left(F_{L}\right)=\infty, \lim _{K \rightarrow \infty}\left(F_{K}\right)=\lim _{L \rightarrow \infty}\left(F_{L}\right)=0$. 
Applying consumption heuristic (3) to constraint (4), the differential equation for the motion of each household's class capital stock becomes the following piecewise equation,

$$
\dot{K}(t, x)=\left\{\begin{array}{l}
-(1+\delta) K(t, x) \text { if } x \geq \ln \left[1+\frac{K(t, x)}{Y(t, x)}\right] \\
-\left(e^{x}-1\right) Y(t, x)-\delta K(t, x) \text { if } 0 \leq x<\ln \left[1+\frac{K(t, x)}{Y(t, x)}\right] \\
(1-\zeta)\left(1-e^{x}\right) Y(t, x)-\delta K(t, x) \text { if } x<0
\end{array}\right.
$$

To explore the growth dynamics underlying (12), we proceed with a two step analysis. In the first step, it is assumed that all agents fall in the same sentiment class. In a second stage, sentiment heterogeneity, in the terms discussed in section 3 , is added to the discussion.

\subsection{Sentiment homogeneity}

To simplify notation, in the sentiment homogeneity scenario, index $x$ is dropped and the analysis is pursued for a single representative agent. A first fundamental result emerges from the straightforward observation of the dynamics underlying equation (12).

Proposition 1 In the neoclassical growth model with consumption-savings decisions determined by consumption heuristic (3), one of two long-term outcomes is obtained: ( i) for $x \geq 0$, the capital stock and the levels of income and consumption fall to zero over time; ( ii) for $x<0$, there is a unique steady-state point such that steadystate levels of capital, income, and consumption, $K^{*}, Y^{*}$ and $C^{*}$, stay positive and constant.

\section{Proof See Appendix A.}

When taking a Cobb-Douglas production function, $Y(t)=A K(t)^{\alpha} L(t)^{1-\alpha}$ with $A>0$ the technology index and $\alpha \in(0,1)$ the output-capital elasticity, the unique steady-state capital level presents itself explicitly as

$$
K^{*}=\left[\frac{(1-\zeta)\left(1-e^{x}\right) A}{\delta}\right]^{1 /(1-\alpha)} L
$$

Expression (13) establishes an obvious relationship between the negative sentiment level and the stock of capital in long-term equilibrium: the stronger the sentiment in absolute value, i.e. the larger the value of $|x|$, the larger will also be the level of $K^{*}$ (which is a straightforward effect of increased savings). The respective steady-state income and consumption levels are,

$$
\begin{gathered}
Y^{*}=A^{1 /(1-\alpha)}\left[\frac{(1-\zeta)\left(1-e^{x}\right)}{\delta}\right]^{\alpha /(1-\alpha)} L \\
C^{*}=A^{1 /(1-\alpha)}\left[e^{x}+\zeta\left(1-e^{x}\right)\right]\left[\frac{(1-\zeta)\left(1-e^{x}\right)}{\delta}\right]^{\alpha /(1-\alpha)} L
\end{gathered}
$$


Unlike capital and income, for which stronger sentiments are undoubtedly a source of higher steady-state values, $C^{*}$ has no trivial relation with $x$; such relation has an inverted U-shape, with a maximum at point

$$
\left(x_{\max } ; C_{\max }^{*}\right)=\left[\ln \left(\frac{1-\zeta-\alpha}{1-\zeta}\right) ; A^{1 /(1-\alpha)}(1-\alpha)\left(\frac{\alpha}{\delta}\right)^{\alpha /(1-\alpha)} L\right]
$$

The maximum point (16) is the solution of $\frac{\partial C^{*}}{\partial x}=0$, and it exists only when constraint $\zeta+\alpha<1$ is satisfied. If this inequality is not satisfied, steady-state consumption increases with the intensification of the negative sentiment throughout the entire range of values that this variable might assume. The steady-state consumption outcome under $\zeta+\alpha<1$ corresponds to the golden rule result (Phelps 1966). This is the long-term level of consumption that cannot be increased by either an increase or a decrease in the savings rate; in the steady-state perspective, a savings rate higher or lower than $s_{\text {gold }}=(1-\zeta)\left(1-e^{x_{\max }}\right)=\alpha$ will signify, respectively, over-savings or under-savings relative to the optimal long-term consumption scenario. The obtained result is precisely the same one derived when computing the golden rule for a trivial capital accumulation constraint outside the consumption heuristic framework, i.e., the exogenous savings rate must coincide with the output-capital elasticity.

One additional result to explore for the neoclassical growth model concerns the speed of convergence to the steady-state, in the steady-state vicinity. For $x<0$ and a Cobb-Douglas production function, this is given by

$$
-\left.\frac{d \dot{K}(t, x)}{d K(t, x)}\right|_{K(t, x)=K^{*}}=-\left[\alpha(1-\zeta)\left(1-e^{x}\right) A\left(\frac{L}{K^{*}}\right)^{1-\alpha}-\delta\right]=(1-\alpha) \delta
$$

The speed of convergence (17) is independent of the degree in which an agent is an ant. It corresponds to the trivial result found for any Solow-like growth equation.

Figure 1 sketches transitional dynamics for the discussed growth model. The case $x<0$ is a typical neoclassical growth outcome, with convergence to a zero-growth steady-state. In the other two cases, there is negative growth and a divergence of the growth process towards the zero capital stock outcome.

Consumption rule (3), combined with capital accumulation equation (12), allows for the determination of the temporal trajectory of consumption under each of the three possible worldview conditions. At this respect, note that, for a given $K(0)=$ $K_{0}$,

$$
K_{0}+\left.Y_{0}\right|_{x \geq \ln \left[1+\frac{K_{0}}{Y_{0}}\right]}>\left.e^{x} Y_{0}\right|_{0 \leq x<\ln \left[1+\frac{K_{0}}{Y_{0}}\right]}>\left.\left[e^{x}+\zeta\left(1-e^{x}\right)\right] Y_{0}\right|_{x<0}
$$

Condition (18) signifies that, for some initial capital level, consumption at $t=0$ is as much higher as the higher the value of the sentiment index. The only segment of the heuristic conducting to positive output and consumption levels in the long-run is the one that performs worst in the short-run. Note that, under the first two consumption functions, consumption falls to zero (because output falls to zero as well). Possible consumption time trajectories are depicted in Fig. 2.

Figure 2 allows for a visual interpretation of the short-term / long-term conflict that emerges in the growth setting under the consumption heuristic. Unlike the optimal 


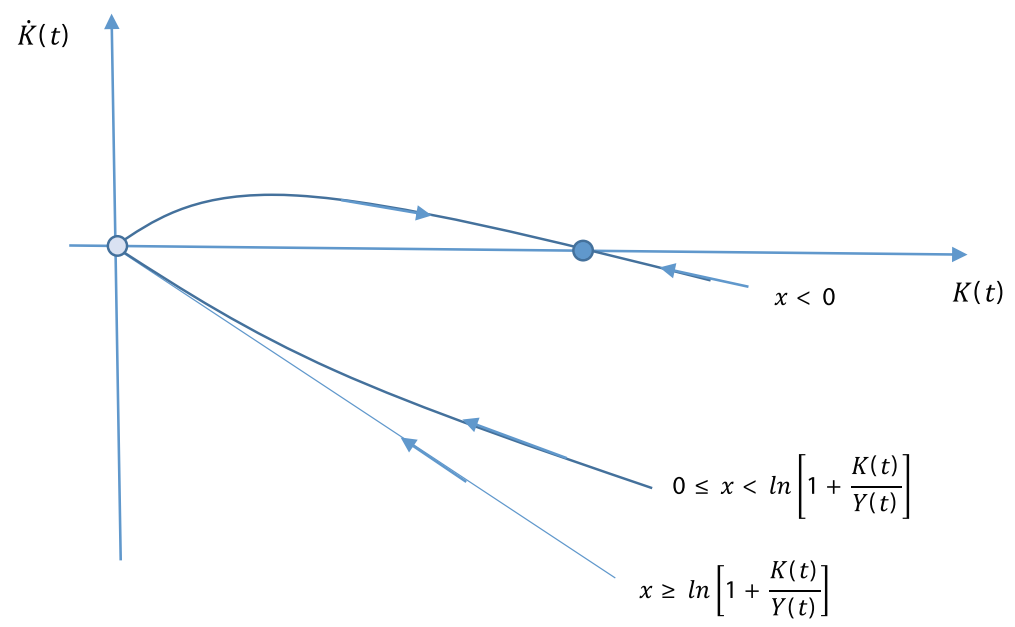

Fig. 1 Phase diagram (neoclassical growth)

planning problem that explicitly considers intertemporal preferences, the assumed consumption heuristic generates a more subtle way of looking at and interpreting the economy's fundamental choice concerning the anticipation or postponing of consumption. The representative agent is endowed, in this case, with a given view of the world; as discussed in Section 3, he can be an ant or he can be a grasshopper. The grasshopper $(x>0)$ is the agent that attributes priority to the possibility of consuming more in the short-run, neglecting the long-term. The ant $(x<0)$ is patient, in the sense that it is willing to sacrifice short-run consumption, thus saving a percentage of the received income, and guaranteeing in this way the perpetuation over time of positive consumption levels.

\subsection{Sentiment heterogeneity}

The heterogeneity assumption brings a fundamental change to the analysis. In an economy exclusively populated by grasshoppers, the values of capital, output and

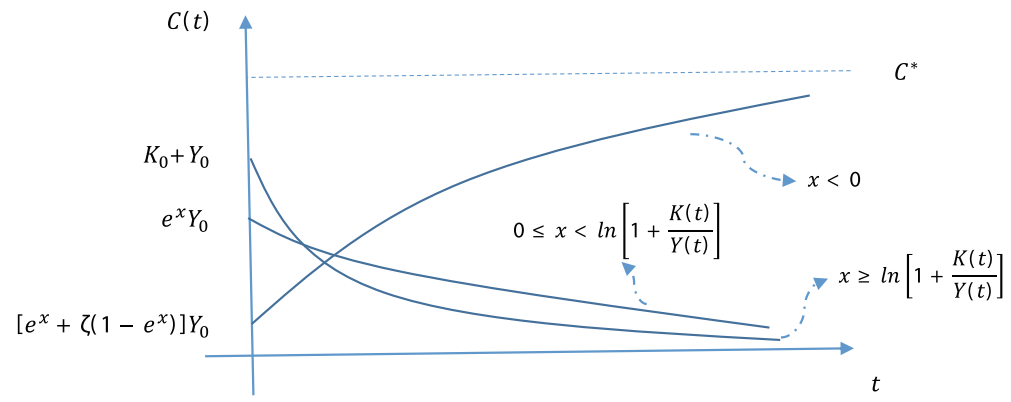

Fig. 2 Consumption path (neoclassical growth) 
consumption fall to zero for all agents. However, a grasshopper in a world with a mixed population will not necessarily suffer a progressive decline of income and consumption levels towards zero, as we discuss below.

Proposition 2 The neoclassical growth model with consumption-savings choices derived from heuristic (3) and with heterogeneity of worldviews yields the following steady-state outcome: (i) agents for whom $x \geq 0$ will consume, in the long-term, their wage income; ( ii) agents for whom $x<0$ will consume, in the long-term, their wage income and the returns they get from the capital they accumulate. The steadystate capital stock is a unique constant positive value, and thus the wage and the capital return rate are also unique constant solutions of the growth problem (and identical across agents).

Proof See Appendix B.

Although one cannot compute a general explicit expression for $K^{*}(x)$, this is feasible for the aggregate stock of capital, i.e., $K^{*}=\int_{-\infty}^{0} K^{*}(x) d x$. To reach this result, first let the percentage of households in the ant classes to be a share $\vartheta \in(0,1)$ of the population; $1-\vartheta$ is, then, the percentage of grasshoppers in the economy. Under a Cobb-Douglas technology, straightforward computation allows to arrive to the following result,

$$
K^{*}=\left\{(1-\zeta)\left(1-e^{\bar{x}}\right) \frac{A}{\delta}[(1-\alpha) \vartheta+\alpha]\right\}^{\frac{1}{1-\alpha}}
$$

with $\bar{x}$ the average sentiment of ants. The aggregate income generated with the stock of capital $K^{*}$ is

$$
Y^{*}=A^{\frac{1}{1-\alpha}}\left\{(1-\zeta)\left(1-e^{\bar{x}}\right) \frac{1}{\delta}[(1-\alpha) \vartheta+\alpha]\right\}^{\frac{\alpha}{1-\alpha}} L
$$

Income, as expressed in (20), is the sum of two terms, namely, the long-run income of ants and the long-run income of grasshoppers,

$$
\begin{gathered}
Y_{\text {ants }}^{*}=F_{L}^{*} \vartheta L+F_{K}^{*} K^{*}=[(1-\alpha) \vartheta+\alpha] Y^{*} \\
Y_{\text {grass. }}^{*}=F_{L}^{*}(1-\vartheta) L=(1-\alpha)(1-\vartheta) Y^{*}
\end{gathered}
$$

It is straightforward to verify that $Y_{\text {ants }}^{*}+Y_{\text {grass. }}^{*}=Y^{*}$. Steady-state consumption levels are also, in this case, decipherable; grasshoppers consume $C_{\text {grass }}^{*}=Y_{\text {grass }}^{*}$. and ants consume $C_{a n t s}^{*}=\left[e^{\bar{x}}+\zeta\left(1-e^{\bar{x}}\right)\right] Y_{a n t s}^{*}$. The overall consumption level is

$$
C^{*}=\left\{1-\left[(1-\zeta)\left(1-e^{\bar{x}}\right)\right][(1-\alpha) \vartheta+\alpha]\right\} Y^{*}
$$

According to result (23), the steady-state consumption-income ratio is a lower than 1 value that benefits from high savings, strong sentiments, and a relatively small share of ants. 
The differential equation that fully represents the motion of the aggregate capital accumulation equation is, in the neoclassical case with sentiment heterogeneity,

$$
\begin{aligned}
\dot{K}(t)= & (1-\zeta) \int_{-\infty}^{0}\left(1-e^{x}\right)\left[F_{L} L(x)+F_{K} K(t, x)\right] d x \\
& -\int_{0}^{\ln \left[1+\frac{K(t, x)}{Y(t, x)}\right]}\left(e^{x}-1\right)\left[F_{L} L(x)+F_{K} K(t, x)\right] d x \\
& -\int_{\ln \left[1+\frac{K(t, x)}{Y(t, x)}\right]}^{+\infty} K(t, x) d x-\delta K(t), \\
K(0, x)= & K_{0}(x) \text { given. }
\end{aligned}
$$

A qualitative evaluation of equation (24) allows us to infer what the typical time trajectory of the capital variable will be. Assuming that all agents share an identical initial capital endowment, there will be a first phase in which capital, and also income, decline as grasshoppers spend their wealth without replacing it through new investment; after a given threshold, the amounts of capital of grasshoppers become irrelevant, and capital accumulation will follow the standard convergence path towards the steady-state of the neoclassical growth model, i.e., there will be convergence to a steady-state of zero growth and positive and constant capital stock. Fig. 3 displays the characterized trajectory, turning it clear how the introduction of the heuristic changes the initial phase of the transitional dynamics of the standard neoclassical growth model.

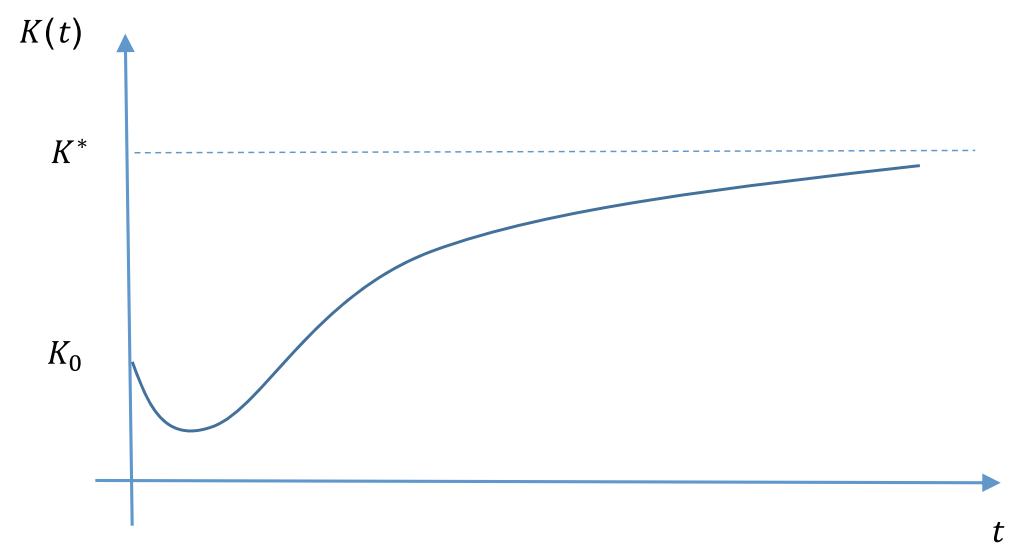

Fig. 3 Growth path in the neoclassical growth model under sentiment heterogeneity 
Taking differential equation (24), we can formally represent the steady-state as the circumstance in which:

$$
\lim _{t \rightarrow \infty} \int_{0}^{\ln \left[1+\frac{K(t, x)}{Y(t, x)}\right]}\left(e^{x}-1\right)\left[F_{L} L(x)+F_{K} K(t, x)\right] d x=\lim _{t \rightarrow \infty} \int_{\ln \left[1+\frac{K(t, x)}{Y(t, x)}\right]}^{+\infty} K(t, x) d x=0
$$

and, therefore, we might present a more detailed version of expression (67) in Appendix B, i.e.,

$$
K^{*}: \lim _{t \rightarrow \infty} \frac{\int_{-\infty}^{0}\left(1-e^{x}\right)\left[F_{L} L(x)+F_{K} K(t, x)\right] d x}{\int_{-\infty}^{0} K(t, x) d x}=\frac{\delta}{1-\zeta}
$$

The singularity of the steady-state is guaranteed, as before, because the outputcapital ratio in the left-hand-side of (26) is a continuous, twice-differentiable, decreasing function, that converges to zero if $K^{*} \rightarrow \infty$ and to infinity if $K^{*}=0$. Consequently, the constant ratio in the right-hand side of (26) is crossed once and only once, implying that $K^{*}$ effectively exists and is unique.

\section{Endogenous growth: the AK model with a twist}

Consider now a simple endogenous growth model under an AK production function. The production function, $Y(t)=A K(t)$, aggregates material inputs into a unique production factor, subject to constant marginal returns; parameter $A>0$ continues to reflect the state of technology. The income of the households in a given sentiment class is given by (5). However, one should note that no labor is associated with the production function and therefore no wages are paid; hence, $Y(t, x)=r(t) K(t, x)=A K(t, x)$. Such a plain specification of the production technology allows for a straightforward presentation of the capital accumulation differential equation and of the consumption function, for each class of agents,

$$
\begin{gathered}
\dot{K}(t, x)=\left\{\begin{array}{l}
-(1+\delta) K(t, x) \text { if } x \geq \ln \left(1+\frac{1}{A}\right) \\
-\left[\left(e^{x}-1\right) A+\delta\right] K(t, x) \text { if } 0 \leq x<\ln \left(1+\frac{1}{A}\right), K(0, x)=K_{0}(x) \text { given } \\
{\left[(1-\zeta)\left(1-e^{x}\right) A-\delta\right] K(t, x) \text { if } x<0}
\end{array}\right. \\
C(t, x)=\left\{\begin{array}{l}
(1+A) K(t, x) \text { if } x \geq \ln \left(1+\frac{1}{A}\right) \\
e^{x} A K(t, x) \text { if } 0 \leq x<\ln \left(1+\frac{1}{A}\right) \\
{\left[e^{x}+\zeta\left(1-e^{x}\right)\right] A K(t, x) \text { if } x<0}
\end{array}\right.
\end{gathered}
$$


As in the neoclassical case, we start the analysis by assuming homogeneous sentiments and then proceed, for further insights, to the heterogeneity case.

\subsection{Sentiment homogeneity}

Take capital accumulation equation (27) for a population of households sharing an identical sentiment level and, for convenience, drop the $x$ index. The characterization of the dynamics involved in (27) might be synthesized in the following proposition:

Proposition 3 If $x \geq 0$, then there is negative growth and convergence to $K^{*}=$ $Y^{*}=C^{*}=0$. If $x<0$, then the growth rate might be either negative, positive, or zero, respectively for $x>\ln \left[1-\frac{\delta}{(1-\zeta) A}\right], x<\ln \left[1-\frac{\delta}{(1-\zeta) A}\right]$, and $x=\ln \left[1-\frac{\delta}{(1-\zeta) A}\right]$. For $x<\ln \left[1-\frac{\delta}{(1-\zeta) A}\right]$, the capital stock, income, and consumption all grow, over time, at positive constant rate

$$
\gamma=(1-\zeta)\left(1-e^{x}\right) A-\delta
$$

Proof See Appendix C.

From (29), it is straightforward to conclude that the higher the value of $x$ in absolute value (the more extreme the sentiment), the faster will be the pace of growth. Figure 4 displays the corresponding phase diagram. In this diagram is reflected the idea that growth is always constant for the AK production technology; growth might be positive, zero, or negative, depending on the value of $x$. Positive growth requires a value of $x$ above a given threshold.

In Fig. 5, the time trajectory of consumption is displayed for each of the three possibilities regarding the value of $x$. The diagram has evident similarities with the one

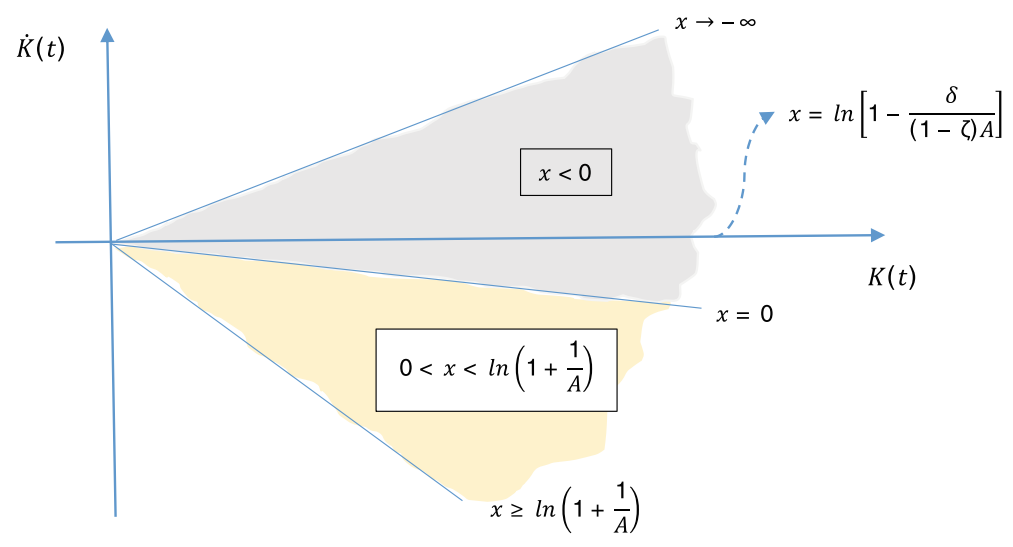

Fig. 4 Phase diagram (AK growth) 


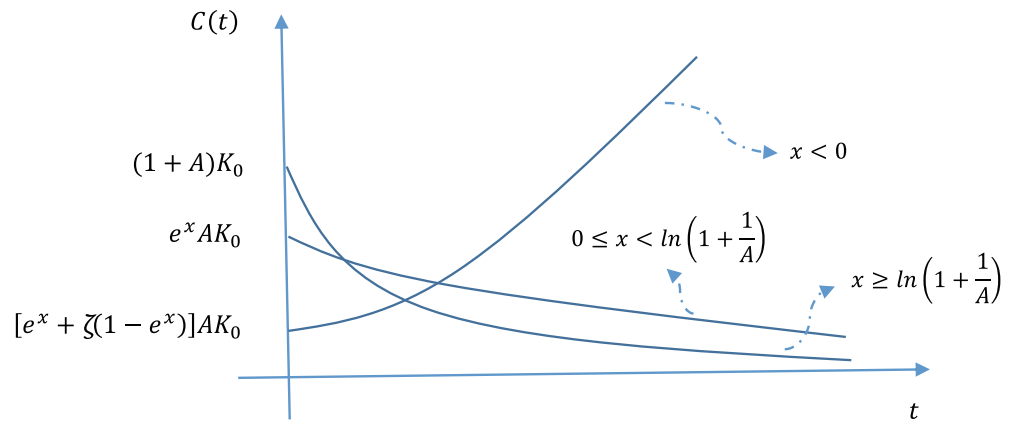

Fig. 5 Consumption path (AK growth)

in Fig. 2. The main difference is that when savings exist, capital and income accumulate at a positive constant rate, allowing consumption also to grow exponentially. An inequality similar to condition (18) applies in the current case, what allows placing the trajectories in Fig. 5 by the order they appear.

Figures 2 and 5 are illustrative of the short-run / long-run conflict that the growth model under the consumption heuristic allows to unveil. This conflict is a timeless theme of discussion in Economics. As J.M. Keynes put it in his General Theory,

"A diminished propensity to consume to-day can only be accommodated to the public advantage if an increased propensity to consume is expected to exist some day. We are reminded of 'The Fable of the Bees' - the gay of tomorrow are absolutely indispensable to provide a raison d' être for the grave of to-day."

Keynes (1936, p. 93).

\subsection{Sentiment heterogeneity}

Assuming sentiment heterogeneity does not change the qualitative steady-state results of the AK model relatively to the above characterization. The reason for this was already explained: differently from the neoclassical model, there is now a single input, which is capital; as grasshoppers spend all their wealth in short-run consumption, they will exhaust their productive resources and will not participate in production in the long-term. Thus, their income and their consumption will effectively fall to zero. In this setting, in the long-term, only redistributive policies will eventually allow for positive grasshoppers' consumption. The generation of income and the growth rate of the economy will be solely in the hands of the ants.

While heterogeneity does not bring any significant novelty to the long-run locus, it introduces changes in terms of transitional dynamics. The income of each group of agents grows at a constant rate over time, meaning the absence of transitional dynamics at the class level. However, the shift of capital from the hands of grasshoppers to the hands of the ants implies that, on the aggregate, capital does not necessarily 
grow at a constant rate. In particular, the equation of motion for the aggregate stock of capital is,

$$
\begin{aligned}
\dot{K}(t)= & A(1-\zeta) \int_{-\infty}^{0}\left(1-e^{x}\right) K(t, x) d x-\int_{0}^{\ln \left(1+\frac{1}{A}\right)}\left(e^{x}-1\right) K(t, x) d x \\
& -\int_{\ln \left(1+\frac{1}{A}\right)}^{+\infty} K(t, x) d x-\delta K(t), \\
K(0, x)= & K_{0}(x) \text { given. }
\end{aligned}
$$

The most striking difference between equation (30) and a similar equation with household homogeneity is that now we will have transitional dynamics in the AK model. The economy will converge to the long-term growth rate

$$
\gamma=(1-\zeta) \frac{\int_{-\infty}^{0}\left(1-e^{x}\right) K^{*}(x) d x}{\int_{-\infty}^{0} K^{*}(x) d x} A-\delta
$$

with $\frac{\int_{-\infty}^{0}\left(1-e^{x}\right) K^{*}(x) d x}{\int_{-\infty}^{0} K^{*}(x) d x}<1$. However, this will not be the growth rate for the entire process of capital accumulation. In a first phase, the presence of individuals who save at a declining rate will imply a growth rate lower than $\gamma$. As the level of capital of such individuals falls to zero, the ants' group becomes dominant and the growth rate rises until it reaches the value in (31). Therefore, although for each household the growth rate is constant over time (positive under $x<\ln \left[1-\frac{\delta}{(1-\zeta) A}\right]$ and null or negative otherwise), the growth rate of the aggregate economy is not constant in the transient phase.

We should highlight, as we have done in the first approach to the AK model, that growth rate (31) is not necessarily a positive value. Only if $\frac{\int_{-\infty}^{0}\left(1-e^{x}\right) K^{*}(x) d x}{\int_{-\infty}^{0} K^{*}(x) d x}<$ $1-\frac{\delta}{(1-\zeta) A}$, will the growth rate be larger than zero. This condition requires the distribution of $x$ to be relatively apart from the state of neutrality. 


\section{Endogenous growth: heuristics for consumption and human capital accumulation}

In this section, we continue the characterization of conventional growth models under consumption rule (3) by extending the analysis to a two-sector endogenous growth model of the Uzawa-Lucas type.

Let $H(t)$ represent the aggregate endowment of human capital in the economy and consider the following production functions for physical goods and for human capital, respectively: $F[K(t), u(t) H(t)] ; G\{[1-u(t)] H(t)\}$, with $u(t)$ the share of human capital allocated to the production of physical goods. Function $F: \mathbb{R}_{+}^{2} \rightarrow \mathbb{R}_{+}$ is a neoclassical production function, and function $G: \mathbb{R}_{+} \rightarrow \mathbb{R}_{+}$is a linear function. Physical capital and human capital accumulation constraints are, respectively,

$$
\begin{gathered}
\dot{K}(t)=F[K(t), u(t) H(t)]-C(t)-\delta K(t), K(0)=K_{0} \text { given } \\
\dot{H}(t)=G\{[1-u(t)] H(t)\}-\delta H(t), H(0)=H_{0} \text { given }
\end{gathered}
$$

As a simplifying assumption, we consider identical depreciation rates for physical goods and for human capital. As above, in the first step of the analysis the homogeneous sentiment case is characterized.

\subsection{Sentiment homogeneity}

In order to maintain the coherence of the analysis, the cognitive constraints that were attached to consumption choices are now extended to human capital allocation decisions. In particular, in the current setting we assume that the intertemporal allocation of human capital across sectors, i.e., the trajectories of $u(t)$ and of its complement, $1-u(t)$, will also be determined by a heuristic that, again, splits households between ants and grasshoppers.

Consider the following linear production technology for human capital:

$$
G\{[1-u(t)] H(t)\}=B[1-u(t)] H(t), B>0
$$

The human capital allocation heuristic to adopt is:

$$
\frac{\dot{u}(t)}{u(t)}=\left\{\begin{array}{c}
0 \text { if } x \geq 0 \\
\frac{1-\alpha}{\alpha} B+B u(t)-\frac{C(t)}{K(t)} \text { if } x<0, u(0)=1-\frac{\delta}{B}
\end{array}\right.
$$

Rule (35) considers two distinct cases. For $x \geq 0$, it is assumed that agents select the simplest possible course of action, i.e., they take an initial value of $u(t)$ such that the distribution of human capital across sectors remains constant over time. Agents for whom $x<0$ are, in this setting, sophisticated agents who opt to allocate optimally human capital over time assuming no a priori knowledge on the rule considered for consumption; the expression for the growth rate of $u(t)$ in the case of the ants' class is the outcome of an optimal control problem. ${ }^{4}$ As we will prove below, $u(t)$ will converge, in the optimization case, to a long-term steady-state level that is lower than

\footnotetext{
${ }^{4}$ See Appendix D for the derivation of this equation.
} 
$u(0)$, meaning that an agent who optimizes will allocate a larger share of human capital to education than one that does not.

The adopted heuristic for human capital allocation intends, as the consumption rule, to translate with some degree of accuracy what empirical evidence allows us to observe. In the case of human capital accumulation, there is significant evidence pointing to the existence of a correlation, among households, between those who are patient and save and those who make planned investments in human capital. By contrast, impatient agents - grasshoppers - prefer to direct their workforce primarily to an income generating activity that allows for immediate consumption gratification rather than investing in human capital that is likely to bring returns in future dates. Patient agents - ants - will plan the future and this plan will materialize in a relatively high investment in education. Furthermore, this interpretation of the behavior of savers postulates that this class of agents puts different cognitive effort in human capital allocation decisions relatively to consumption-savings choices. The latter are assumed intuitive and rule-based, while education choices are subject to careful deliberation. Studies confirming these stylized facts include Cadena and Keys (2015) and Dohmen et al. (2016).

Next, define the ratio between capital variables, $\Omega(t) \equiv \frac{K(t)}{H(t)}$, and write, under Cobb-Douglas technology, the corresponding dynamic equation:

$$
\frac{\dot{\Omega}(t)}{\Omega(t)}=A\left[\frac{u(t)}{\Omega(t)}\right]^{1-\alpha}-\frac{C(t)}{K(t)}-B[1-u(t)]
$$

The consumption-capital ratio is obtainable, in our setting, directly from the consumption heuristic,

$$
\frac{C(t)}{K(t)}=\left\{\begin{array}{l}
1+A\left[\frac{u(t)}{\Omega(t)}\right]^{1-\alpha} \quad \text { if } x \geq \ln \left\{1+\frac{1}{A}\left[\frac{\Omega(t)}{u(t)}\right]^{1-\alpha}\right\} \\
e^{x} A\left[\frac{u(t)}{\Omega(t)}\right]^{1-\alpha} \quad \text { if } 0 \leq x<\ln \left\{1+\frac{1}{A}\left[\frac{\Omega(t)}{u(t)}\right]^{1-\alpha}\right. \\
{\left[e^{x}+\zeta\left(1-e^{x}\right)\right] A\left[\frac{u(t)}{\Omega(t)}\right]^{1-\alpha} \quad \text { if } x<0}
\end{array}\right\}
$$

The dynamics of the two-sector model can be inspected from system (35)-(36), which is, then, composed of three pieces, namely,

$$
\begin{aligned}
& \text { i) If } x \geq \ln \left\{1+\frac{1}{A}\left[\frac{\Omega(t)}{u(t)}\right]^{1-\alpha}\right\} \text {, } \\
& \left\{\begin{array}{l}
u(t)=1-\frac{\delta}{B} \\
\frac{\dot{\Omega}(t)}{\Omega(t)}=-(1+\delta)
\end{array}\right. \\
& \left\{\begin{array}{l}
u(t)=1-\frac{\delta}{B} \\
\frac{\dot{\Omega}(t)}{\Omega(t)}=-\left(e^{x}-1\right) A\left[\frac{1-\frac{\delta}{B}}{\Omega(t)}\right]^{1-\alpha}-\delta
\end{array}\right.
\end{aligned}
$$


iii) If $x<0$,

$$
\left\{\begin{array}{l}
\frac{\dot{u}(t)}{u(t)}=\frac{1-\alpha}{\alpha} B+B u(t)-\left[e^{x}+\zeta\left(1-e^{x}\right)\right] A\left[\frac{u(t)}{\Omega(t)}\right]^{1-\alpha} \\
\frac{\dot{\Omega}(t)}{\Omega(t)}=(1-\zeta)\left(1-e^{x}\right) A\left[\frac{u(t)}{\Omega(t)}\right]^{1-\alpha}-B[1-u(t)]
\end{array}\right.
$$

The following proposition summarizes growth dynamics.

Proposition 4 In the Uzawa-Lucas growth model under heuristic behavior, if $x \geq 0$ then the steady-state levels of income and consumption will be zero; if $x<0$, then the economy converges, through a saddle-path stable trajectory, towards a balanced growth path such that both forms of capital, income and consumption grow at a constant rate. Under Cobb-Douglas technology this rate is

$$
\gamma^{*}=\frac{(1-\zeta)\left(1-e^{x}\right)}{\alpha} B-\delta
$$

\section{Constraint}

$$
\frac{\delta}{B}<\frac{(1-\zeta)\left(1-e^{x}\right)}{\alpha}<1
$$

must hold in order to guarantee an interior solution and a positive growth rate.

Proof See Appendix E.

One may plot, for the Uzawa-Lucas model, a figure in the same spirit of Fig. 5. Figure 6 makes use of equation (37) to draw the time trajectory of consumption. The trajectory initiates its course, for a given pair of values $\left(K_{0}, H_{0}\right)$, at one of the points $C_{0}=\left\{1+A\left[\frac{u_{0}}{\Omega_{0}}\right]^{1-\alpha}\right\} K_{0}, C_{0}=e^{x} A\left[\frac{u_{0}}{\Omega_{0}}\right]^{1-\alpha} K_{0}, C_{0}=\left[e^{x}+\zeta(1-\right.$ $\left.\left.e^{x}\right)\right] A\left[\frac{u_{0}}{\Omega_{0}}\right]^{1-\alpha} K_{0}$. These points are ordered from the highest to the lowest value, given the constraints in equation (37). Therefore, as in the one-sector model, the representative agent might focus on the short-run and expect a high level of income, which leads to a high short-term consumption level that rapidly begins to fall, or, alternatively, he may choose to adopt an ant behavior, thus saving and guaranteeing a long-term consumption level that grows at constant rate (41).

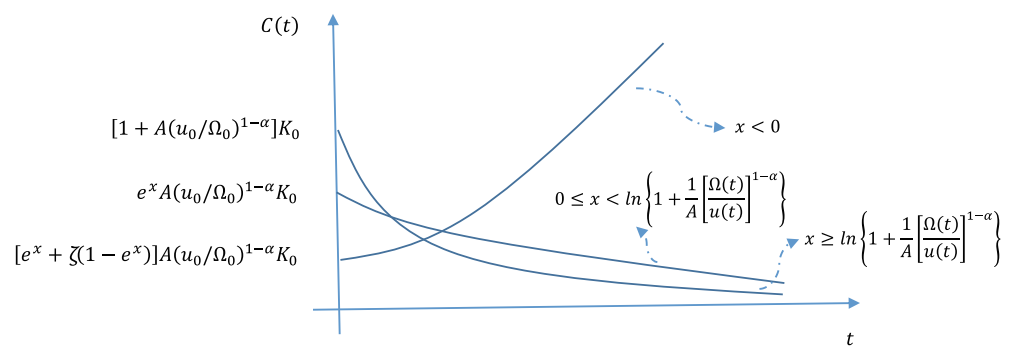

Fig. 6 Consumption path (Two-sector endogenous growth) 


\subsection{Sentiment heterogeneity}

The first point to highlight when introducing heterogeneity in the heuristic UzawaLucas framework is aligned with the initial note emphasized in the case of the onesector neoclassical model. Agents can be separated into three categories, given their worldview: $x<0 ; 0 \leq x<\ln \left\{1+\frac{1}{A}\left[\frac{\Omega(t, x)}{u(t, x)}\right]^{1-\alpha}\right\} ; x \geq \ln \left\{1+\frac{1}{A}\left[\frac{\Omega(t, x)}{u(t, x)}\right]^{1-\alpha}\right\}$. Variables $\Omega(t, x)$ and $u(t, x)$ represent the physical capital - human capital ratio and the share of human capital allocated to the production of physical goods for the set of individuals endowed with sentiment $x$. Agents in the second circumstance will evolve to the third, because in that case the ratio $\Omega(t, x)$ falls to zero as time progresses. Therefore, only two profiles of households will eventually subsist in the long-term.

The agents in sentiment class $x$ will earn the following income:

$$
Y(t, x)=w(t) u(t, x) H(t, x)+r(t) K(t, x)
$$

The wage rate and the rental rate correspond, in this case, to the following marginal returns of each form of capital:

$$
\begin{gathered}
w(t)=F_{H}=(1-\alpha) A\left[\frac{\Omega(t)}{u(t)}\right]^{\alpha} \\
r(t)=F_{K}=\alpha A\left[\frac{u(t)}{\Omega(t)}\right]^{1-\alpha}
\end{gathered}
$$

In the current setting, $\Omega(t)$ and $u(t)$ are, respectively, the aggregate physical capital - human capital ratio and the average share of human capital allocated to production, i.e.,

$$
\frac{\Omega(t)}{u(t)}=\frac{\int_{x \in \mathbb{R}} K(t, x) d x}{\int_{x \in \mathbb{R}} u(t, x) H(t, x) d x}
$$

Steady-state outcomes are summarized as follows:

Proposition 5 In the Uzawa-Lucas heuristic growth model, the economy's balanced growth path is such that grasshoppers will consume a constant amount, which corresponds to their wage, while the consumption of ants grows at a constant rate, which is also the growth rate of income and both forms of capital.

Proof See Appendix F.

On the aggregate, the growth rate of the economy is, in this case,

$$
\gamma^{*}=B \frac{(1-\vartheta) L \frac{\delta}{B} H_{0}(x)+\frac{1-\zeta}{\alpha} \int_{-\infty}^{0}\left(1-e^{x}\right) H^{*}(x) d x}{(1-\vartheta) L H_{0}(x)+\int_{-\infty}^{0} H^{*}(x) d x}-\delta
$$


The fraction term in expression (47) corresponds to the overall share of human capital allocated to the education sector. Growth rate (47) is a weighted average of the growth rates of each sentiment class. This expression encloses two particular cases: (i) for an economy solely populated by grasshoppers $(\vartheta=0)$, the expression reduces to $\gamma^{*}=0$; ( ii) for an economy exclusively populated by ants $(\vartheta=1)$, the respective

growth expression is $\gamma^{*}=\frac{1-\zeta}{\alpha} \frac{\int_{-\infty}^{0}\left(1-e^{x}\right) H^{*}(x) d x}{\int_{-\infty}^{0} H^{*}(x) d x} B-\delta$, with $\frac{\int_{-\infty}^{0}\left(1-e^{x}\right) H^{*}(x) d x}{\int_{-\infty}^{0} H^{*}(x) d x}<1$. Evidently, in this last case, if we go back to the beginning of the analysis and take a unique $x<0$ value, the just presented growth rate reduces to the expression in (41).

From the discussion so far, we can highlight that the three inspected models deliver three different steady-state results: $(i)$ in the AK model, consumption by ants grows at a positive rate and consumption by grasshoppers falls to zero; $(\mathrm{ii})$ in the one-sector neoclassical growth model, consumption by ants and consumption by grasshoppers are constant values but they differ between classes; ( $i$ i i) in the two-sector human capital model, the consumption by grasshoppers is constant and the consumption by ants grows at the economy's constant growth rate.

\section{The age of automation and robotics: a brief assessment}

A final growth model to assess in the current analysis is a framework that considers not only the standard notion of capital that complements labor in production, but also a second type of capital, which serves as a substitute for labor. This second type of capital corresponds to machines and processes that replace humans, i.e., robots. ${ }^{5}$

Start by letting $R(t)$ be the amount of automated capital used in production and continue to consider $K(t)$ as conventional physical capital. The production function for physical goods is, when contemplating both capital inputs,

$$
Y(t)=A K(t)^{\alpha}[L+R(t)]^{1-\alpha}
$$

Parameters $A, L, \alpha$ are defined as in previous analyses. As in Prettner (2016), we consider exogenous shares of savings directed to investment in each of the capital sectors: let $\sigma$ be the share of savings allocated to physical capital production and its complement, $1-\sigma$, the share of savings allocated to the automation sector. Capital accumulation equations are typical growth constraints, namely,

$$
\begin{gathered}
\dot{K}(t)=\sigma[Y(t)-C(t)]-\delta K(t), \quad K(0)=K_{0} \text { given } \\
\dot{R}(t)=(1-\sigma)[Y(t)-C(t)]-\delta R(t), \quad R(0)=R_{0} \text { given }
\end{gathered}
$$

Equations (49) and (50) take, as underlying assumption, that the technology for producing one or the other type of capital is the same. For simplicity, we assume also identical depreciation rates for the two capital types.

\footnotetext{
${ }^{5}$ The role of automation and robotics as an engine of long-term growth has been explored in recent literature. See, e.g., Benzell et al. (2015), Sachs et al. (2015), Prettner (2016), Gasteiger and Prettner (2017), and Gomes (2019).
} 
In this new setting, and continuing to assume competitive markets, the following returns on labor and capital hold:

$$
\begin{gathered}
w(t)=r_{R}(t)=F_{L}=F_{R}=(1-\alpha) A\left[\frac{K(t)}{L+R(t)}\right]^{\alpha} \\
r(t)=F_{K}=\alpha A\left[\frac{L+R(t)}{K(t)}\right]^{1-\alpha}
\end{gathered}
$$

Wages and gross returns on robotic capital are identical since they are assumed as perfect substitutes in production. Note that the accumulation of automated capital lowers the labor income share, i.e.,

$$
\frac{w(t) L}{Y(t)}=(1-\alpha) \frac{L}{L+R(t)}
$$

The consumption-savings heuristic is, in the robot setting,

$$
C(t)=\left\{\begin{array}{l}
K(t)+R(t)+Y(t) \text { if } x \geq \ln \left[1+\frac{K(t)+R(t)}{Y(t)}\right] \\
e^{x} Y(t) \text { if } 0 \leq x<\ln \left[1+\frac{K(t)+R(t)}{Y(t)}\right] \\
{\left[e^{x}+\zeta\left(1-e^{x}\right)\right] Y(t) \text { if } x<0}
\end{array}\right.
$$

implying the following accumulation constraints for each of the capital types,

$$
\begin{gathered}
\dot{K}(t)=\left\{\begin{array}{l}
-\sigma[K(t)+R(t)]-\delta K(t) \text { if } x \geq \ln \left[1+\frac{K(t)+R(t)}{Y(t)}\right] \\
-\sigma\left(e^{x}-1\right) Y(t)-\delta K(t) \text { if } 0 \leq x<\ln \left[1+\frac{K(t)+R(t)}{Y(t)}\right] \\
\sigma(1-\zeta)\left(1-e^{x}\right) Y(t)-\delta K(t) \text { if } x<0
\end{array}\right. \\
\dot{R}(t)=\left\{\begin{array}{l}
-(1-\sigma)[K(t)+R(t)]-\delta R(t) \text { if } x \geq \ln \left[1+\frac{K(t)+R(t)}{Y(t)}\right] \\
-(1-\sigma)\left(e^{x}-1\right) Y(t)-\delta R(t) \text { if } 0 \leq x<\ln \left[1+\frac{K(t)+R(t)}{Y(t)}\right] \\
(1-\sigma)(1-\zeta)\left(1-e^{x}\right) Y(t)-\delta R(t) \text { if } x<0
\end{array}\right.
\end{gathered}
$$

Repeating the same procedure of analysis as in all previous cases, we start by assuming a representative agent endowed with some sentiment level, and then we proceed to the sentiment heterogeneity case.

\subsection{Sentiment homogeneity}

The main result associated with the version of the growth model under appreciation is as follows:

Proposition 6 In the growth model with robotic capital and with consumption determined by the assumed heuristic, the steady-state involves the following features: ( $i)$ If $x \geq 0$, then income and consumption decline towards zero; ( ii) If $x<0$, then the two capital inputs, income and consumption will converge to a balanced growth path where the common constant growth rate is

$$
\gamma=\sigma^{\alpha}(1-\sigma)^{1-\alpha}(1-\zeta)\left(1-e^{x}\right) A-\delta
$$


Proof See Appendix G.

In the short-run, this model exhibits properties that are similar to those previously discussed in other versions of the growth model, i.e., initial values of consumption for each of the three rules are such that the one generating better short-run results is the one that is less favorable in the long-run and vice-versa. Again, Keynes' fable of the bees citation is meaningful.

Next, we evaluate the automation-growth model under sentiment heterogeneity.

\subsection{Sentiment heterogeneity}

Income is, for some sentiment group $x$,

$$
Y(t, x)=F_{L}[L(x)+R(t, x)]+F_{K} K(t, x)
$$

Income level (58) is the weighted sum of the returns on labor, robotic capital, and physical capital. Recall that returns on labor and returns on robots are identical.

Proposition 7 In the growth model with robotic capital, with consumption determined by heuristic (3), and with a population containing both ants and grasshoppers, the following steady-state outcome is derived: ( i) grasshoppers would presumably consume a constant amount, which would correspond to the received competitive wage, although because in the long-term labor is replaced by machines in production, they are displaced from the productive process and earn no income; (ii) ants will access a consumption level that grows, for each class $x$, at rate (57).

Proof See Appendix H.

In the growth and automation model, aggregate dynamics might be condensed in the following equations,

$$
\begin{aligned}
\dot{K}(t)= & \sigma(1-\zeta) \int_{-\infty}^{0}\left(1-e^{x}\right) Y(t, x) d x-\sigma \int_{0}^{\ln \left[1+\frac{K(t, x)+R(t, x)}{Y(t, x)}\right]}\left(e^{x}-1\right) Y(t, x) d x \\
& -\sigma \int^{+\infty}[K(t, x)+R(t, x)] d x-\delta K(t), \\
K(t)= & \int_{x \in \mathbb{R}} K\left(1+\frac{K(t, x)+R(t, x)}{Y(t, x)}\right]
\end{aligned}
$$




$$
\begin{aligned}
\dot{R}(t)= & (1-\sigma)(1-\zeta) \int_{-\infty}^{0}\left(1-e^{x}\right) Y(t, x) d x-(1-\sigma) \int_{0}^{\ln \left[1+\frac{K(t, x)+R(t, x)}{Y(t, x)}\right]}\left(e^{x}-1\right) Y(t, x) d x \\
& -\sigma \int_{\ln \left[1+\frac{K(t, x)+R(t, x)}{Y(t, x)}\right]}^{+\infty}[K(t, x)+R(t, x)] d x-\delta R(t) \\
R(t)= & \int_{x \in \mathbb{R}} R(t, x) d x, R(0)=R_{0} \text { given }
\end{aligned}
$$

The equations indicate, as in the AK model, that there will be an initial transient phase of growth below the steady-state rate, given the fall in the capital levels of agents in the $x \geq 0$ classes. In the long-term, physical capital, robotic capital, income and consumption will grow at the rate determined by the capital accumulation process of ants. The growth rate of the economy is

$\gamma=\sigma^{\alpha}(1-\sigma)^{1-\alpha}(1-\zeta) A\left\{(1-\alpha) \frac{\sigma}{1-\sigma} \frac{\int_{-\infty}^{0}\left(1-e^{x}\right)\left[L(x)+R^{*}(x)\right] d x}{\int_{-\infty}^{0} K^{*}(x) d x}+\alpha\right\}-\delta$

Equation (61) allows us to understand that, as the distribution of sentiments skews right (i.e., the sentiment distribution allows for a higher concentration of ants at more extremist positions), the steady-state growth rate increases.

\section{Conclusion}

In this paper, we have revisited some of the most noteworthy economic growth models, namely, the one-sector neoclassical growth model, the AK endogenous growth model, the two-sector endogenous growth model with human capital, and a twosector model with physical capital and robotic capital. These frameworks were addressed under the exact same supply-side structure of analysis as they are typically approached in the literature. The meaningful difference relatively to mainstream research in the field was the substitution of the household intertemporal planning apparatus by a consumption heuristic.

The baseline idea is that households are cognitively constrained and, therefore, they lack the resources to formulate intertemporal plans in long horizons. Hence, they select a static rule from a short menu of possibilities, a choice that is contingent on their view-of-the-world or sentiment about intertemporal consumption. At a first glance, replacing optimal choices by a static consumption-savings rule might be interpreted as a return to the simplistic Solow-like framework with a constant savings rate. The investigation pursued in this paper reveals, however, that this is 
not quite so. In fact, there are important and substantive insights about intertemporal choice, transitional dynamics, steady-state outcomes, and behavior heterogeneity that the proposed setting allows us to contemplate and discuss.

Concerning transitional dynamics, the evident outcome, in every model, is the conflict between the short-term and the long-term; what agents choose to be - ants or grasshoppers - determines their intertemporal preference, with grasshoppers privileging current consumption and ants securing the perpetuation of consumption over time. The distribution of agents across the ant and the grasshopper states determines the pace of growth as the economy converges to the steady-state.

The distribution of the agents across the two states is also capital in shaping the steady-state. Regarding the steady-state, though, the different models lead to distinct outcomes, with ants and grasshoppers following a variety of potential diverse consumption paths. The main findings are systematized in Table 1. Note, in particular, the coincidence of outcomes between the AK growth model and the model with robotic capital; although they are distinct in the transient phase, they converge to a same type of long-run locus: in the growth model with robotic capital, the economy converges to a long-run scenario where humans are fully replaced by machines and, hence, no labor input exists and no wages are paid; the only income that is generated in the balanced growth path is capital income, to which only ants have access.

Admittedly, this paper leaves many questions unanswered or only partially answered. The main goal is to launch the debate on how the replacement of sophisticated consumption plans, plans that agents in fact do not pursue, by straightforward decision rules, changes the growth theory landscape. Such debate can continue by associating to the analysis many other features commonly found in the discussion of the determinants of growth. Future work should address population growth, financial literacy, technology diffusion, heterogeneous productivity, and decentralized interaction, in the context of growth models involving the selected heuristic and eventual other consumption-savings rules closer to actual behavior than intertemporal planning.

Table 1 Synthesis of steady-state results

\begin{tabular}{|c|c|c|}
\hline & Ants & Grasshoppers \\
\hline $\begin{array}{l}\text { One-sector } \\
\text { neoclassical } \\
\text { growth model }\end{array}$ & $\begin{array}{l}\text { Constant consumption level } \\
\text { (wage + capital returns) }\end{array}$ & $\begin{array}{l}\text { Constant consumption level } \\
\text { (wage) }\end{array}$ \\
\hline $\begin{array}{l}\text { AK endogenous } \\
\text { growth model }\end{array}$ & $\begin{array}{l}\text { Constant consumption growth } \\
\text { (growing capital returns, zero } \\
\text { wage) }\end{array}$ & $\begin{array}{l}\text { Zero consumption (zero cap- } \\
\text { ital returns, zero wage) }\end{array}$ \\
\hline $\begin{array}{l}\text { Two-sector } \\
\text { endogenous } \\
\text { growth model }\end{array}$ & $\begin{array}{l}\text { Constant consumption growth (grow- } \\
\text { ing capital returns, constant wage) }\end{array}$ & $\begin{array}{l}\text { Constant consumption level } \\
\text { (constant wage) }\end{array}$ \\
\hline $\begin{array}{l}\text { Growth model with } \\
\text { robotic capital }\end{array}$ & $\begin{array}{l}\text { Constant consumption growth (grow- } \\
\text { ing capital returns, zero wage) }\end{array}$ & $\begin{array}{l}\text { Zero consumption (zero cap- } \\
\text { ital returns, zero wage) }\end{array}$ \\
\hline
\end{tabular}


Acknowledgments Financial support from CEFAGE research center, under FCT (Portuguese Foundation for Science and Technology) strategic program UID/ECO/04007/2019, and from MacroViews project (Lisbon Polytechnic Institute), is gratefully acknowledged. I thank participants in the CEFAGE seminar series, in which a first version of the paper was presented. I also thank the insightful comments of two anonymous referees, which led to a substantial revision of the paper, and the thorough English editing that the journal's editorial team has provided. The usual disclaimer applies.

Funding Information Funding: This study was funded by CEFAGE research center, under FCT (Portuguese Foundation for Science and Technology) strategic program UID/ECO/04007/2019, and by MacroViews project (Lisbon Polytechnic Institute)

\section{Compliance with Ethical Standards}

Conflict of interests The author declares that he has no conflict of interest.

\section{Appendix A: Proof of proposition 1}

For $x \geq 0$, the process of capital accumulation may initiate under one of two dynamic rules, depending on whether $x<\ln \left[1+\frac{K(0)}{Y(0)}\right]$ or $x \geq \ln \left[1+\frac{K(0)}{Y(0)}\right]$. In the first of these two cases, the agent adopts the middle capital accumulation rule in heuristic (3); otherwise, the first rule, such that capital accumulation grows at the constant negative rate $1+\delta$, is followed. Observe, as well, that, in both cases, households will not invest and the level of capital will progressively fall to zero. Given the properties of the neoclassical production function, the value of the ratio $\frac{K(t)}{Y(t)}$ will also decline over time and, as a result, someone starting at the second capital accumulation dynamic rule will necessarily pass onto the first one at a given point in time (a point that is as much further away in time as the smaller is the value of $x$ ). Therefore, in the long-term, as long as $x \geq 0$, capital depletion will invariably occur at rate $1+\delta$, which obviously implies zero steady-state levels of income and consumption, given the production technology and the consumption heuristic.

For $x<0$, we are faced with a Solow-like capital accumulation constraint, with the constant savings rate given by $(1-\zeta)\left(1-e^{x}\right)$. In this case, it is trivial to determine a unique zero-growth steady-state point by solving $\dot{K}(t)=0$. The solution is

$$
K^{*}: \frac{Y^{*}}{K^{*}}=\frac{\delta}{(1-\zeta)\left(1-e^{x}\right)}
$$

The steady-state output-capital ratio, $\frac{Y^{*}}{K^{*}}$, is, under the neoclassical specification, a continuous, twice-differentiable, decreasing function, which diverges to infinity for $K^{*}=0$ and converges to zero whenever $K^{*} \rightarrow \infty$. Therefore, it crosses the constant value in the right hand side of (62) once and only once. If $K^{*}$ is unique, positive and constant, then $Y^{*}$ and $C^{*}$ are also unique positive and constant values, given the production function and the consumption rule. 


\section{Appendix B: Proof of proposition 2}

Start by observing that income in a given sentiment class is presentable as in equation (5). The main point to highlight concerning this equation is that all agents, regardless of their sentiment, will receive the same wage, $w(t)$, and the same return rate from capital, $r(t)$, because they are identical to one another except, eventually, for the value of $x$. This argument is precisely what makes the analysis under heterogeneous sentiments relevant: everyone will always get an income regardless of the trajectory followed by the capital variable, as long as there is at least one ant among grasshoppers. Agents who suffer a complete depletion of their capital stock will continue to be able to consume, because they continue to receive a wage for the participation in the productive activity.

If $x \geq 0$, then $K(t, x) \rightarrow 0$, and the income of the agents in the specific sentiment class converges to the steady-state outcome

$$
Y^{*}(x)=w^{*} L(x)
$$

The steady-state wage level is

$$
w^{*}=F_{L}\left(\int_{-\infty}^{0} K^{*}(x) d x, L\right)
$$

In the Cobb-Douglas specification,

$$
w^{*}=(1-\alpha) A\left(\frac{\int_{-\infty}^{0} K^{*}(x) d x}{L}\right)^{\alpha}
$$

Under the heuristic, the consumption equality that subsists in the steady-state will be, as long as $x \geq 0, C^{*}(x)=K^{*}(x)+Y^{*}(x)$. Because $K^{*}(x)=0$, the long-term level of consumption of any class of grasshoppers in this economy is identical to the respective income, as is expressed in (63). Grasshoppers will take advantage, in the long-run, of the presence of ants in the economy; they can work for them (ants will be those who hold all capital in the steady-state) and continue to consume their wage income level at each period.

With respect to $x<0$, the capital accumulation dynamic equation of households in some sentiment class $x$ is

$$
\dot{K}(t, x)=(1-\zeta)\left(1-e^{x}\right)[w(t) L(x)+r(t) K(t, x)]-\delta K(t, x)
$$

The steady-state value of the capital stock is the value of $K^{*}(x)$ such that

$$
\frac{w^{*} L(x)+r^{*} K^{*}(x)}{K^{*}(x)}=\frac{\delta}{(1-\zeta)\left(1-e^{x}\right)}
$$


with $w^{*}$ defined in (64) or (65), and

$$
r^{*}=F_{K}\left(\int_{-\infty}^{0} K^{*}(x) d x, L\right)=\alpha A\left(\frac{L}{\int_{-\infty}^{0} K^{*}(x) d x}\right)^{1-\alpha}
$$

To determine $K^{*}(x)$ explicitly, it would be necessary to solve a system of dimension equal to the number of sentiment classes that possibly exists for the ant type of households. Nevertheless, the simple observation of expression (67) indicates that the right-hand side of the equation is a constant value, while the left-hand side is, as is for (62), a continuous, twice-differentiable, decreasing function that falls from infinity to zero as we make $K^{*}(x)$ to vary from zero to infinity. Hence, the two sides of (67) cross once and only once at some positive $K^{*}(x)$ value, which signifies that we guarantee the existence of a unique steady-state amount of $K^{*}(x)$, and, consequently, also unique steady-state levels of income and consumption.

\section{Appendix C: Proof of Proposition 3}

The examination of differential equation (27) directly suggests the result in the proposition: the two first rules in the capital accumulation equation yield negative growth and a convergence to a zero capital long-term state. Note that unlike what one has observed in the neoclassical growth model, now the threshold between the two first dynamic rules in the heuristic is a constant value, meaning that there is no transition between rules as the stock of capital falls. This, however does not change the fact that, in both cases, the absence of savings and investment throws the economy to an

extinction state. For $x<0$, there is a constant growth rate $\gamma=\frac{\dot{K}(t, x)}{K(t, x)}$ that is perpetuated over time. For this growth rate to be positive, the sentiment level must be not only negative but sufficiently strong, in absolute value, in order to guarantee $\gamma>0$; this condition is equivalent to the one in the proposition setting an upper bound on the value of $x$.

\section{Appendix D: Derivation of the differential equation representing the motion of the human capital share in the Uzawa-Lucas model $(x<0$}

Let the current-value Hamiltonian function for the intertemporal Uzawa-Lucas growth problem be written as follows, with $p(t)$ and $q(t)$ the co-state variables associated, respectively, to physical capital and human capital,

$$
\begin{aligned}
\mathbf{H}[K(t), H(t), u(t), p(t), q(t)]= & p(t)\{F[K(t), u(t) H(t)]-C(t)-\delta K(t)\} \\
& +q(t)(G\{[1-u(t)] H(t)\}-\delta H(t))
\end{aligned}
$$


First-order optimality conditions are as follows:

$$
\begin{gathered}
\frac{\partial \mathbf{H}(t)}{\partial u(t)}=0 \Rightarrow \frac{F_{u}}{-G_{u}}=\frac{q(t)}{p(t)} \\
\dot{p}(t)=\rho p(t)-\frac{\partial \mathbf{H}(t)}{\partial K(t)} \Rightarrow \dot{p}(t)=\left(\rho+\delta-F_{K}\right) p(t) \\
\dot{q}(t)=-\frac{\partial \mathbf{H}(t)}{\partial H(t)} \Rightarrow \dot{q}(t)=\left(\rho+\delta-G_{H}\right) q(t)-F_{H} p(t)
\end{gathered}
$$

and the transversality conditions come

$$
\lim _{t \rightarrow \infty} K(t) e^{-\rho t} p(t)=\lim _{t \rightarrow \infty} H(t) e^{-\rho t} q(t)=0
$$

where $\rho>0$ is the intertemporal discount rate. Defining $Q(t) \equiv \frac{p(t)}{q(t)}$, equations (71) and (72) can be condensed in a unique equation for the dynamics of ratio $Q(t)$,

$$
\frac{\dot{Q}(t)}{Q(t)}=G_{H}-F_{K}+F_{H} Q(t)
$$

Equation (74) might be further simplified by resorting to (70), i.e.,

$$
\frac{\dot{Q}(t)}{Q(t)}=G_{H}-F_{K}-F_{H} \frac{G_{u}}{F_{u}}
$$

Further insights require specifying functional forms for the production functions. Consider a Cobb-Douglas production function for the goods sector and a linear production function for the human capital sector. The second is already displayed in (34). The first one is

$$
F[K(t), u(t) H(t)]=A K(t)^{\alpha}[u(t) H(t)]^{1-\alpha}, A>0, \alpha \in(0,1)
$$

Under (34) and (76), we rewrite equation (75) as

$$
\frac{\dot{Q}(t)}{Q(t)}=B-\alpha A\left[\frac{u(t) H(t)}{K(t)}\right]^{1-\alpha}
$$

and optimality condition (70) becomes,

$$
Q(t)=(1-\alpha) \frac{A}{B}\left[\frac{K(t)}{u(t) H(t)}\right]^{\alpha}
$$

From (78) one draws the following relation between growth rates,

$$
\frac{\dot{u}(t)}{u(t)}=\frac{1}{\alpha} \frac{\dot{Q}(t)}{Q(t)}+\frac{\dot{K}(t)}{K(t)}-\frac{\dot{H}(t)}{H(t)}
$$

Replacing (77), (32), and (33), into (79), an equation of motion for the optimal allocation of human capital across sectors is obtained, which is the equation in rule (35) for $x<0$. 


\section{Appendix E: Proof of Proposition 4}

Under systems (38) or (39), it is straightforward to notice that the ratio $\Omega(t)$ declines towards zero with the passage of time. This observation implies that variables income and consumption will both converge to a steady-state of complete exhaustion, as mentioned in the proposition.

Only system (40) involves no trivial dynamics. For this system, we can compute steady-state values and analyze transitional dynamics in the vicinity of the steady-state, given a Cobb-Douglas technology. Straightforward algebra allows for calculating the steady-state value of the human capital share allocated to the goods sector. To derive such result, just consider $\dot{\Omega}(t)=\dot{u}(t)=0$,

$$
u^{*}=1-\frac{(1-\zeta)\left(1-e^{x}\right)}{\alpha}
$$

Given (80), in order to exist an interior solution it is required that the following condition holds: $(1-\zeta)\left(e^{x}-1\right)<\alpha$. The physical capital - human capital ratio will be, in the long-term equilibrium,

$$
\Omega^{*}=\left(\frac{1}{\alpha} \frac{B}{A}\right)^{1 /(1-\alpha)} u^{*}
$$

Replacing the human capital share (80) into the human capital accumulation constraint, (33), one immediately derives the steady-state growth rate of human capital, which is also the balanced growth rate of physical capital, since $\Omega^{*}$ is constant. Furthermore, given the shape of the production function and the consumption heuristic, the mentioned growth rate is also the steady-state growth rate of these aggregates.

To prove that dynamic system (40) is saddle-path stable, we linearize it in the vicinity of the steady-state, thus computing the following matricial system:

$$
\left[\begin{array}{c}
\dot{u}(t) \\
\dot{\Omega}(t)
\end{array}\right]=B\left[\begin{array}{cc}
\alpha u^{*}-\frac{(1-\alpha)^{2}}{\alpha} & \frac{1-\alpha}{\alpha}\left[1-\alpha\left(1-u^{*}\right)\right] \frac{u^{*}}{\Omega^{*}} \\
\Omega^{*}+(1-\alpha)\left(1-u^{*}\right) \frac{\Omega^{*}}{u^{*}} & -(1-\alpha)\left(1-u^{*}\right)
\end{array}\right]\left[\begin{array}{c}
u(t)-u^{*} \\
\Omega(t)-\Omega^{*}
\end{array}\right]
$$

The determinant and the trace of the Jacobian matrix in system (82) are, respectively,

$$
\operatorname{Det}(J)=-\frac{1-\alpha}{\alpha} B^{2} u^{*} ; \operatorname{Tr}(J)=B\left(u^{*}-\frac{1-\alpha}{\alpha}\right)
$$

what implies that the eigenvalues of $J$ are $\lambda_{1}=B u^{*}$ and $\lambda_{2}=-\frac{1-\alpha}{\alpha} B$. With one negative and one positive eigenvalues, one confirms that the system is saddle-path stable. $^{6}$

\footnotetext{
${ }^{6}$ Note, in this case, that saddle-path stability guarantees convergence to the balanced growth path. This occurs because the representative agent chooses $u(t)$ optimally and, thus, he is capable of triggering an initial jump that places this control variable over the stable trajectory, which is then followed until the steady-state locus is reached.
} 


\section{Appendix F: Proof of proposition 5}

For every $x \geq 0$, the share of human capital allocated to the production of physical goods is the constant value $u(t, x)=1-\frac{\delta}{B}$ and the stock of physical capital declines over time to zero. Hence, consumption of grasshoppers will be, in the steady-state,

$$
C^{*}(x)=F_{H}^{*} u^{*}(x) H^{*}(x)=(1-\alpha) A\left(\frac{\Omega^{*}}{u^{*}}\right)^{\alpha}\left(1-\frac{\delta}{B}\right) H_{0}(x), \forall x \geq 0
$$

where

$$
\frac{\Omega^{*}}{u^{*}}=\frac{\int_{-\infty}^{0} K^{*}(x) d x}{(1-\vartheta) L\left(1-\frac{\delta}{B}\right) H_{0}(x)+\int_{-\infty}^{0} u^{*}(x) H^{*}(x) d x}
$$

In $(85),(1-\vartheta) L$ represents the number of grasshoppers. Examining result (84), one realizes that $C^{*}(x)$ is positive and constant. As in the neoclassical growth model, grasshoppers take advantage of the fact that there are ants who save and apply their capital in production, so that grasshoppers have the possibility of working and receiving a wage, which they integrally apply, at each period, in consumption.

Let us now explore the steady-state result for the ants' classes. Under $x<0$, the relevant dynamic system for agents in class $x$ is, adapting from system (40),

$$
\left\{\begin{array}{l}
\frac{\dot{u}(t, x)}{u(t, x)}=\frac{1-\alpha}{\alpha} B+B u(t, x)-\left[e^{x}+\zeta\left(1-e^{x}\right)\right][w(t) u(t, x) H(t, x)+r(t) K(t, x)] \\
\frac{\dot{\Omega}(t, x)}{\Omega(t, x)}=(1-\zeta)\left(1-e^{x}\right)[w(t) u(t, x) H(t, x)+r(t) K(t, x)]-B[1-u(t, x)]
\end{array}\right.
$$

Solving $\dot{\Omega}(t, x)=\dot{u}(t, x)=0$, one gets expressions for the share of human capital $u^{*}(x)$ and for the long-term growth rate $\gamma^{*}(x)$ that mimic (80) and (41), respectively. Growth rate $\gamma^{*}(x)$ is the growth rate of both forms of capital and, given the income expression and the consumption function, also the steady-state growth rate of these two variables (income and consumption).

\section{Appendix G: Proof of proposition 6}

The observation of differential equations (55) and (56) indicates that, under $x \geq 0$, there is no capital accumulation in the steady-state. This is true for both types of capital. Therefore, no income and no consumption will subsist in the steady-state in an economy of grasshoppers that give priority to the short-run.

The third rule in the consumption heuristic introduces interesting dynamics into the growth process and allows us to perceive that, in this case, endogenous growth emerges. Defining ratio $\Phi(t) \equiv \frac{K(t)}{R(t)}$, the following equation of motion is derived,

$$
\frac{\dot{\Phi}(t)}{\Phi(t)}=(1-\zeta)\left(1-e^{x}\right) A\left[\frac{L}{K(t)}+\frac{1}{\Phi(t)}\right]^{1-\alpha}[\sigma-(1-\sigma) \Phi(t)]
$$


In this case, for $x<0$, the capital accumulation constraint is

$$
\frac{\dot{K}(t)}{K(t)}=\sigma(1-\zeta)\left(1-e^{x}\right) A\left[\frac{L}{K(t)}+\frac{1}{\Phi(t)}\right]^{1-\alpha}-\delta
$$

From the two above equations, it is possible to derive the steady-state growth of physical capital. Start by noticing that a constant steady-state ratio $\Phi^{*}$ corresponds, given (87), to:

$$
\Phi^{*}=\frac{\sigma}{1-\sigma}
$$

From differential equation (88) one may, then, write the steady-state growth rate of physical capital as

$$
\gamma_{K}=\sigma(1-\zeta)\left(1-e^{x}\right) A\left(\frac{L}{K^{*}}+\frac{1-\sigma}{\sigma}\right)^{1-\alpha}-\delta
$$

Because $K^{*}$ grows at a constant rate in the steady-state and $L$ remains constant, ratio $\frac{L}{K^{*}}$ falls to zero, and this observation directs us to the explicit growth rate of physical capital, which is (57). This is also the steady-state growth rate of robots, as one understands by noticing that under $x<0$,

$$
\frac{\dot{R}(t)}{R(t)}=(1-\sigma)(1-\zeta)\left(1-e^{x}\right) A \Phi(t)\left[\frac{L}{K(t)}+\frac{1}{\Phi(t)}\right]^{1-\alpha}-\delta
$$

Replacing $\Phi(t)$ in (91) by its steady-state value and remarking once again that the labor-capital ratio falls to zero, the steady-state evaluation of the equation of motion for robotic capital allows us to unveil, once again, growth rate (57). Given that the production technology is Cobb-Douglas, then income also grows, at the balanced growth path, at the same rate, which is also the growth rate of consumption, once we take consumption heuristic (54).

\section{Appendix H: Proof of Proposition 7}

From differential equations (49) and (50), it is straightforward to observe that $K(t, x)$ and $R(t, x)$ converge to zero for every non-negative $x$. Thus, the income and consumption levels of grasshoppers will tend to

$$
Y^{*}(x)=C^{*}(x)=F_{L}^{*} L(x)=(1-\alpha) A\left[\frac{\int_{-\infty}^{0} K^{*}(x) d x}{L+\int_{-\infty}^{0} R^{*}(x) d x}\right]^{\alpha} L(x)
$$

Because $L$ is constant and $K$ and $R$ grow at a same constant rate in the steady-state, for every $x<0$, grasshoppers consume a positive constant amount in the steady-state (as long as labor is not entirely replaced by robotic capital). Furthermore, notice that 
$\int^{0}$

$\int_{-\infty}^{0} K^{*}(x) d x$

$\frac{-\infty}{0}=\Phi^{*}$ and, thus, expression (92) might in a simpler way be displayed $L+\int R^{*}(x) d x$

as: $Y^{*}(x)=C^{*}(x)=(1-\alpha) A\left(\frac{\sigma}{1-\sigma}\right)^{\alpha} L(x)$.

For the ants' classes, a positive endogenous growth rate is determinable. The growth rate of physical capital held by agents in class $x, \forall x<0$, is

$$
\begin{aligned}
\frac{\dot{K}(t, x)}{K(t, x)} & =\sigma(1-\zeta)\left(1-e^{x}\right) \frac{Y(t, x)}{K(t, x)}-\delta \Leftrightarrow \\
\frac{\dot{K}(t, x)}{K(t, x)} & =\sigma(1-\zeta)\left(1-e^{x}\right)\left[F_{L} \frac{L(x)+R(t, x)}{K(t, x)}+F_{K}\right]-\delta \Leftrightarrow \\
\frac{\dot{K}(t, x)}{K(t, x)} & =\sigma(1-\zeta)\left(1-e^{x}\right)\left\{F_{L}\left[\frac{L(x)}{K(t, x)}+\frac{1}{\Phi(t, x)}\right]+F_{K}\right\}-\delta
\end{aligned}
$$

In the steady-state, term $\frac{L(x)}{K(t, x)}$ converges to zero and $\Phi^{*}(x)=\frac{\sigma}{1-\sigma}$; the wage rate and the rate of return on capital are, respectively, $w^{*}=F_{L}^{*}=(1-\alpha) A\left(\frac{\sigma}{1-\sigma}\right)^{\alpha}$ and $r^{*}=F_{K}^{*}=\alpha A\left(\frac{1-\sigma}{\sigma}\right)^{1-\alpha}$. Thus, the evaluation of (93) in the steady-state locus conduct directly to growth rate expression (57).

A similar reasoning can be taken for capital variable $R(t, x)$, leading exactly to the same outcome,

$$
\begin{aligned}
& \frac{\dot{R}(t, x)}{R(t, x)}=(1-\sigma)(1-\zeta)\left(1-e^{x}\right) \frac{Y(t, x)}{R(t, x)}-\delta \Leftrightarrow \\
& \frac{\dot{R}(t, x)}{R(t, x)}=(1-\sigma)(1-\zeta)\left(1-e^{x}\right)\left[F_{L} \frac{L(x)+R(t, x)}{R(t, x)}+F_{K} \frac{K(t, x)}{R(t, x)}\right]-\delta \Leftrightarrow \\
& \frac{\dot{R}(t, x)}{R(t, x)}=(1-\sigma)(1-\zeta)\left(1-e^{x}\right)\left\{F_{L}\left[\frac{L(x)}{R(t, x)}+1\right]+F_{K} \Phi(t, x)\right\}-\delta
\end{aligned}
$$

To confirm the identical outcome, observe that $\lim _{t \rightarrow \infty}\left\{F_{L}\left[\frac{L(x)}{R(t, x)}+1\right]+F_{K}\right\}=$ $F_{L}^{*}+F_{K}^{*} \frac{\sigma}{1-\sigma}=A\left(\frac{\sigma}{1-\sigma}\right)^{\alpha}$. Replacing this steady-state value into (94), we get (57). If both forms of capital follow a same balanced growth path, then it is straightforward to infer, as before, that income and consumption share the same long-term growth rate.

\section{References}

Acemoglu D, Cao D (2015) Innovation by Entrants and Incumbents. Journal of Economic Theory 157:255-294

Acemoglu D, Akcigit U, Alp H, Bloom N, Kerr W (2018) Innovation, reallocation, and growth. American Economic Review 108:3450-3491 
Aghion P, Howitt P (1992) A Model of Growth through Creative Destruction. Econometrica 60:323-351

Aghion P, Akcigit U, Howitt P (2015) Lessons from Schumpeterian Growth Theory. American Economic Review 105:94-99

Aghion P, Roulet A (2014) Growth and the Smart State. Annual Review of Economics 6:913-926

Akcigit U (2017) Economic Growth:, the Past, the Present, and the Future. Journal of Political Economy 125:1736-1747

Akcigit U, Kerr WR (2018) Growth through Heterogeneous Innovations. Journal of Political Economy 126:1374-1443

Akcigit U, Celik MA, Greenwood J (2016) Buy, Keep, or Sell:, Economic Growth and the Market for Ideas. Econometrica 84:943-984

Benhabib J, Perla J, Tonetti C (2014) Catch-up and Fall-Back through Innovation and Imitation. Journal of Economic Growth 19:1-35

Benzell SG, Kotlikoff LJ, LaGarda G, Sachs JD (2015) Robots Are Us: Some Economics of Human Replacement NBER working paper ${ }^{\circ} 20941$

Brock WA, Hommes CH (1997) A Rational Route to Randomness. Econometrica 65:1059-1095

Buera FJ, Lucas RE (2018) Idea Flows and Economic Growth. Annual Review of Economics 10:315-345

Cadena BC, Keys BJ (2015) Human Capital and the Lifetime Costs of Impatience, American Economic Journal: Economic Policy, vol. 7, pp. 126-153

Campbell JY, Mankiw NG (1990) Permanent income, current income, and consumption. Journal of Business \& Economic Statistics 8:265-279

Cass D (1965) Optimum Growth in an Aggregative Model of Capital Accumulation. Review of Economic Studies 32:233-240

Ciarli T, Lorenz A, Valente M, Savona M (2019) Structural Changes and Growth Regimes. Journal of Evolutionary Economics 29:119-176

Dawid H, Harting P, Neugart M (2014) Economic Convergence: Policy Implications from a Heterogeneous Agent Model. Journal of Economic Dynamics and Control 44:54-80

Dawid H, Harting P, Neugart M (2018) Cohesion Policy and Inequality Dynamics: Insights from a Heterogeneous Agents Macroeconomic Model. Journal of Economic Behavior \& Organization 150:220-255

Dawid H, Harting P, Hoog S, Neugart M (2019) Macroeconomics with heterogeneous agent models: fostering transparency, reproducibility and replication. Journal of Evolutionary Economics 29:467538

De Grauwe P (2011) Animal Spirits and Monetary Policy. Economic Theory 47:423-457

Deaton A (1992) Household Saving in LDCs: Credit Markets, Insurance and Welfare. Scandinavian Journal of Economics 94:253-273

Dohmen T., Enke B, Falk A, Huffman D, Sunde U (2016) Patience and the Wealth of Nations Working Paper 2016-012, Human Capital and Economic Opportunity Working Group

Dosi G, Fagiolo G, Roventini A (2010) Schumpeter Meeting Keynes: a Policy-friendly Model of Endogenous Growth and Business Cycles. Journal of Economic Dynamics and Control 34:1748-1767

Dosi G, Fagiolo G, Napoletano M, Roventini A (2013) Income Distribution, Credit and Fiscal Policies in an Agent-based Keynesian Model. Journal of Economic Dynamics and Control 37:1598-1625

Dosi G, Fagiolo G, Napoletano M, Roventini A, Treibich T (2015) Fiscal and Monetary Policies in Complex Evolving Economies. Journal of Economic Dynamics and Control 52:166-189

Dosi G, Napoletano M, Roventini A, Stiglitz JE, Treibich T (2017) Rational Heuristics? Expectations and Behaviors in Evolving Economies with Heterogeneous Interacting Agents. LEM papers series 2017/31 Sant'Anna School of advanced Studies. Pisa, Italy

Dosi G, Roventini A (2019) More is Different ... Complex! The Case for Agent-based Macroeconomics. Journal of Evolutionary Economics 29:1-37

Dosi G, Roventini A, Russo E (2019) Endogenous Growth and Global Divergence in a Multi-country Agent-based Model. Journal of Economic Dynamics and Control 101:101-129

Ellison G, Fudenberg D (1993) Rules of Thumb for Social Learning. Journal of Political Economy 101:612-643

Gabaix X (2014) A Sparsity-based Model of Bounded Rationality. Quarterly Journal of Economics 129:1661-1710..

Gasteiger E, Prettner K (2017) A note on automation, stagnation, and the implications of a robot tax freie universitat Berlin, discussion paper 2017/17 
Gerhard P, Gladstone JJ, Hoffmann AOI (2018) Psychological Characteristics and Household Savings Behavior:, the Importance of Accounting for Latent Heterogeneity. Journal of Economic Behavior \& Organization, 148:66-82

Gigerenzer G, Todd PM (1999) Simple Heuristics that Make Us Smart. Oxford University Press, New York

Gigerenzer G, Selten R (2002) Bounded Rationality: the Adaptive Toolbox Cambridge, MA: MIT Press

Gigerenzer G (2008) Rationality for Mortals: How People Cope with Uncertainty New York: Oxford University Press

Gigerenzer G, Brighton H (2009) Homo Heuristicus:, Why Biased Minds Make Better Inferences. Topics in Cognitive Science 1:107-143

Gigerenzer G, Gaissmaier W (2011) Heuristic Decision Making. Annual Review of Psychology 62:451482

Gomes O (2019) Growth in the Age of Automation:, Foundations of a Theoretical Framework. Metroeconomica 70:77-97

Grossman GM, Helpman E (1991) Innovation and Growth in the Global Economy Cambridge Mass. MIT Press

Grossman GM, Helpman E (2015) Globalization and Growth. American Economic Review 105:100-104

Grossman GM, Helpman E (2018) Growth, trade, and inequality. Econometrica 86:37-83

Guerini M, Napoletano M, Roventini A (2018) No Man is an Island:, the Impact of Heterogeneity and Local Interactions on Macroeconomic Dynamics. Economic Modelling 68:82-95

Haldane AG, Turrell AE (2019) Drawing on Different Disciplines:, Macroeconomic Agent-based Models. Journal of Evolutionary Economics 29:39-66

Jaimovich N, Rebelo S (2017) Nonlinear Effects of Taxation on Growth. Journal of Political Economy 125:265-291

Jones CI (1995) R\&D-Based Models of Economic Growth. Journal of Political Economy 103:759-784

Keynes JM (1936) The General Theory of Employment, Interest, and Money 2018 edition Cham, Switzerland: Palgrave Macmillan

Kim YJ, Song J (2014) Romer Meets Heterogeneous Workers in an Endogenous Growth Model. Hitotsubashi Journal of Economics 55:121-146

Koopmans TC (1965) On the Concept of Optimal Economic Growth in The Econometric Approach to Development Planning Amsterdam: North Holland

Krusell P, Smith AA (1996) Rules of thumb in macroeconomic equilibrium. a quantitative analysis. Journal of Economic Dynamics and Control 20:527-558

Lamperti F, Dosi G, Napoletano M, Roventini A, Sapio A (2018) Faraway, So Close: Coupled Climate and Economic Dynamics in an Agent-based Integrated Assessment Model. Ecological Economics 150:315-339

Lettau M, Uhlig H (1999) Rules of Thumb versus Dynamic Programming. American Economic Review 89:148-174

Lucas RE (1988) On the Mechanics of Economic Development. Journal of Monetary Economics 22:3-42

Lucas RE (2009) Ideas and Growth. Economica 76:1-19

Lucas RE (2015) Human Capital and Growth. American Economic Review 105:85-88

Lucas RE, Moll B (2014) Knowledge Growth and the Allocation of Time. Journal of Political Economy 122:1-51

Martin A, Ventura J (2012) Economic Growth with Bubbles. American Economic Review 102:3033-3058

Phelps ES (1966) Golden Rules of Economic Growth New York: Norton

Prettner K (2016) The Implications of Automation for Economic Growth and the Labor Share of Income Vienna University of Technology working papers in Economic Theory and Policy, $\mathrm{n}^{\circ}$ 04/2016

Rebelo S (1991) Long-Run Policy Analysis and Long-Run Growth. Journal of Political Economy 99:500521

Romer PM (1987) Growth Based on Increasing Returns Due to Specialization. American Economic Review 77:56-62

Romer PM (1990) Endogenous Technological Change. Journal of Political Economy 98:S71-S102

Sachs JD, Benzell S, LaGarda G (2015) Robots: Curse or Blessing?A Basic Framework NBER working pape, $n{ }^{\circ} 21091$

Sequeira TN, Gil PM, Afonso O (2018) Endogenous Growth and Entropy. Journal of Economic Behavior and Organization 154:100-120

Simon HA (1955) A Behavioral Model of Rational Choice. Quarterly Journal of Economics 69:99-118 
Solow RM (1956) A Contribution to the Theory of Economic Growth. Quarterly Journal of Economics 70:65-94

Stokey NL (2015) Catching Up and Falling Behind. Journal of Economic Growth 20:1-36

Swan TW (1956) Economic Growth and Capital Accumulation. Economic Record 32:334-361

Tversky A, Kahneman D (1974) Judgement Under Uncertainty:, Heuristics and Biases. Science 185:11241131

Uzawa H (1965) Optimum Technical Change in an Aggregative Model of Economic Growth. International Economic Review 6:18-31

Weber CE (2000) Rule-of-thumb Consumption, Intertemporal Substitution, and Risk Aversion. Journal of Business \& Economic Statistics 18:497-502

Weber CE (2002) Intertemporal Non-separability and Rule of Thumb Consumption. J Monet Econ 49:293-308

Winter JK, Schlafmann K, Rodepeter R (2012) Rules of Thumb in Life-cycle Saving Decisions. Economic Journal 122:479-501

Zeira J, Zoabi H (2015) Economic Growth and Sector Dynamics. European Economic Review 79:1-15

Publisher's note Springer Nature remains neutral with regard to jurisdictional claims in published maps and institutional affiliations. 